\title{
An Analysis of Tritium Releases to the Atmosphere by a CTR
}

October 1975

Prepared for the U.S. Energy

Research and Development Administration

under Contract E(45-1): 1830 
This report was prepared as an account of work sponsored by the United States Government. Neither the United States nor the United States Energy Research and Development Administration, nor any of their emplovees. nor any of their contractors, subcontractors, or their employees, makes any warranty, express or implied. or assumes any legal liability or responsibility for the accuracy, completeness or usefulness of any information, apparatus, product or process disclosed, or represents that its use would not infringe privately owned rights.

\section{PACIFIC NORTHWEST LABORATORY}

operated by

BATTELLE

for the

U.S. ENERGY RESEARCH AND DEVELOPMENT ADMINISTRATION

Under Contract $E(45-1)-1830$

Price: Printed Copy \$5.45; Microfiche \$2.25 
BNWL-1938

UC -20

AN ANALYSIS OF TRITIUM RELEASES

TO THE ATMOSPHERE BY A CTR

by

David S. Rennèt, William F. Sanduskyt, and M. Terry Dana*

tApplied Meteorology Section and

*Atmospheric Dynamics and Chemistry Section

Atmospheric Sciences Department

October 1975

Battelle, Pacific Northwest Laboratories

Richland, Washington 99352 


\section{ACKNOWLEDGEMENTS}

This report summarizes a study conducted by Battelle, Pacific Northwest Laboratories (Battelle-Northwest) for the Division of Controlled Thermonuclear Research of the Energy Research and Development Administration under Contract No. AT(45-1)-1830. The authors wish to thank Mssrs. J. L. Heffter and G. J. Ferber of the National Oceanic and Atmospheric Administration's Environmental Research Laboratories, Silver Spring, Maryland, for providing the computer analysis of local and regional ground level normalized concentrations. Mr. R. K. Woodruff of the Atmospheric Sciences Department, Battelle-Northwest, provided many helpful comments and suggestions. 
LIST OF FIGURES

LIST OF TABLES

i i i

NOMENCLATURE

iv

ABSTRACT

$\mathrm{v}$

1

1. INTRODUCTION 3

2. THE BEHAVIOR OF TRITIUM IN THE ENVIRONMENT 5

2.1 Emissions from Controlled Thermonuclear Reactors 5

2.2 Transformation Processes in the Atmosphere 6

2.3 Global Transport of Tritium and the Hydrometeorological Cycle

3. SCAVENGING OF TRITIUM BY PRECIPITATION 9

3.1 Theory of Scavenging 9

3.2 Below-Cloud Equilibrium Scavenging 15

$\begin{array}{lll}3.3 & \text { In-Cloud Scavenging } & 17\end{array}$

3.4 Alternatives and Limitations on Mode1s 19

4. ANALYSIS OF TRITIUM CONCENTRATIONS IN THE HYDROSPHERE 21

4.1 Phase 1: Estimated Average Ground-level Concentrations Near the Plant 21

4.2 Phase 2: Estimated Average Ground-level Concentrations in the Eastern Half of United States 24

4.3 Average Surface Water Concentrations near a CTR Plant 24

4.4 Phase 3: Estimated Latitudinal and Global Average Atmospheric and Surface Water Tritium Concentrations $\quad 30$

4.5 Summary of Normal Operation Impacts 42

4.6 Accidental Releases of Tritium 44

5. CONCLUSIONS AND FUTURE RESEARCH NEEDS 49

6. REFERENCES 51 


\section{LIST OF FIGURES}

Figure

Figure 3.1

Figure 3.2

Figure 3.3

Figure 4.1

Figure 4.2

Figure 4.3

Figure 4.4

Figure 4.5

Figure 4.6

Figure 4.7
Title

Amount of Tritium in Rainwater for Equilibrium and Non-Equilibrium Conditions as a Function of Distance.

$\mathrm{Q}(\mathrm{x}) / \mathrm{Q}_{\mathrm{O}}$ as a Function of Release Height (h), Rainfall Rate $(\mathrm{J})$, and Downwind Distance $(\mathrm{x})$.

Henry's Constant $\left(\mathrm{H}^{*}\right)$ as a Function of Temperature.

Ground-Level Air Concentration Values of Tritium for an Area Near Morris, Illinois.

Ground-Level Air Concentration Values of Tritium for the Eastern United States.

Normalized Surface Water Concentration $\left(\chi_{g} / Q\right)$ as a Function of Distance ( $x)$.

Schematic of the Box Model Approach to Computing Atmospheric and Surface Water Tritium Concentrations by Latitude Belt.

Mean Meridional Transport of Water Vapor and Surface Water Based on Values Published in Sellers (1965).

Variation of Normalized Tritiated Water Concentration Per Unit Area.

The Effect of Rainfall Rate on Normalized Surface Water Concentration.
Page

13

14

18

23 
TABLE 3.1 Input Conditions Used in EPAEC Linear Model

TABLE 3.2

Values of Ratio and Fraction of Raindrop Drop Scavenging

TABLE $4.1 \quad$ Surface Water Tritium Concentration $\left(x_{g}\right)$ for
Various Distances from the Source.

TABLE 4.2 Parameters Used for Computation of Atmospheric and Surface Water Tritium Concentrations by Latitude Belt (From, Sellers, 1965)

TABLE 4.3 Average Ground-Leve1 Atmospheric and Surface Water Concentrations by Latitude Belt for Land Masses $(W=0.5 \mathrm{~m})$ and Oceans $(W=75 \mathrm{~m})$ Assuming a 1 Ci-year-1 Release in Latitude $30^{\circ}-50^{\circ} \mathrm{N}$.

TABLE 4.4 Average Ground-Level Atmospheric and Surface Water Concentrations by Latitude Belt for Land and Ocean Areas Incorporating Global "Background".

TABLE 4.5 Summary of Maximum Allowable Emissions (MAE) of Tritium to the Atmosphere by a Normal CTR Operation Based on Atmospheric $\left(x_{a}\right)$ and Surface Water $\left(x_{g}\right)$ Concentrations.

TABLE 4.6 Surface Water Concentrations of Tritium During Occurrence of Maximum Rainfall Rates Following a CTR Accident. 


\section{NOMENCLATURE}

Symbo 1

A

C

D

E

$\mathrm{H}^{\prime}$

$\mathrm{He}$

HT

HTO

$\mathrm{J}$

k

K

L

MAE

Mev

MPC

$\mathrm{P}$

Q

$Q_{a}$

$Q_{S}$

$Q_{\mathrm{t}}$

$r$

$\overline{\mathrm{R}}$

$t$

$\mathrm{T}$

$\overline{\mathrm{u}}$

$v_{t}$

W

W

$\bar{W}$

$\mathrm{x}$

y

Definition

area of precipitation, $\mathrm{m}^{2}$

raindrop concentration, mass $-\mathrm{cm}^{-3}$

deuterium

annual areal evaporation, $\mathrm{m}^{3}-\mathrm{yr}^{-1}$

Henry's Law solubility factor, mass $-\mathrm{cm}^{-3}$

helium

tritium gas

tritiated water vapor

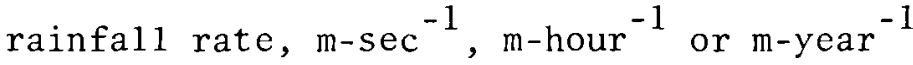

effective scavenging coefficient, $\sec ^{-1}$

mass transfer coefficient

effective thickness of a polluted layer, m

maximum allowable emission

million electron volts

maximum permissible concentration

annual areal precipitation, $\mathrm{m}^{3}-\mathrm{yr}^{-1}$

tritium point source emission rate to the atmosphere, $\mathrm{Ci}-\mathrm{yr}^{-1}$

tritium area source emission rate to the atmosphere, $\mathrm{Ci}-\mathrm{yr}^{-1}$

tritium area source emission rate to surface water, Ci-yr ${ }^{-1}$

accidental tritium release, $\mathrm{Ci}$

raindrop radius, $\mathrm{cm}$

rain flux, mass $-\mathrm{cm}^{-2}-\mathrm{sec}^{-1}$

time

tritium

mean wind speed, $\mathrm{m}-\mathrm{sec}^{-1}$

terminal velocity of fall of a raindrop, $\mathrm{cm}-\mathrm{sec}^{-1}$

depth of atmospheric precipitable water, $m$

depth of the groundwater mixing layer, $m$

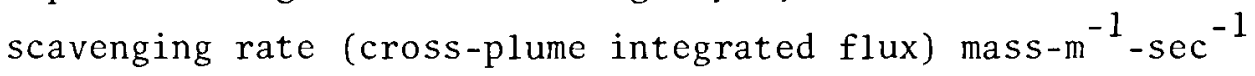

distance downwind, $m$

distance crosswind, $m$ 
$\varepsilon$

$\Lambda$

$n$

$\rho_{\mathrm{a}}$

$\rho_{\mathrm{w}}$

$\sigma$

$x_{a}$

$x_{g}$

a

c 1

eq

g

g1

w

y

Z collection efficiency

constant scavenging coefficient, $\mathrm{sec}^{-1}$

neutron

absolute humidity $\left(\mathrm{m}^{3} \mathrm{H}_{2} \mathrm{O}-\mathrm{m}^{3}\right.$ air $\left.{ }^{-1}\right)$

density of water, gm-liter ${ }^{-1}$

standard deviation of plume parameter, $\mathrm{m}$

atmospheric pollutant concentration, $\mathrm{Ci}-\mathrm{m}^{-3}$

surface water pollutant concentration, Ci-liter ${ }^{-1}$

Subscripts

atmospheric

centerline

equilibrium

surface water

ground-level

water

horizontal

vertical 
AN ANALYSIS OF TRITIUM RELEASES

TO THE ATMOSPHERE BY A CTR

\author{
David S. Renné, William F. Sandusky, and M. Terry Dana \\ ATMOSPHERIC SCIENCES DEPARTMENT \\ Battelle, Pacific Northwest Laboratories \\ Richland, Washington 99352
}

\begin{abstract}
Removal by atmospheric processes of routinely and accidentally released tritium from a controlled thermonuclear reactor (CTR) has been investigated. Based on previous studies, the assumed form of the tritium for this analysis was HTO, or tritiated water vapor. Assuming a CTR operation in Morris, Illinois, surface water and ground-level air concentration values of tritium were computed for three space (or time) scales: local (50 Km of a plant), regional (up to $1000 \mathrm{Km}$ of the plant), and global.

Results of this analysis show that within $50 \mathrm{Km}$ of the plant atmospheric concentrations of tritium will be the limiting factor for routine releases. On the regional and global scale, surface water concentrations tend to become the limiting factor. However, both air and surface water tritium concentrations are estimated to be below existing standards during normal commercial CTR operations.
\end{abstract}

An analysis for an accidental release of tritium shows surface water concentrations in the vicinity of the plant to be quite high after a rainfa11. Concentrations could be 1 or 2 orders of magnitude above accepted standards if the amount of accidentally released tritium now postulated (10 Kgms) occurred. 
Future work should be directed toward better understanding of the atmospheric scavenging processes of tritiated gases, the regional and global transport of tritium in the hydrometeorologic cycle, and better definition of the probability and magnitude of extreme climatic events that would result in excessive concentrations of tritium in the atmosphere and surface water supplies. 


\section{INTRODUCTION}

The Controlled Thermonuclear Reactor (CTR) is a new technology in electrical power production that could provide future generations with an almost unlimited source of electricity and at the same time produce only a minimum of environmental impact. With our present supplies of fuels used in power generation dwindling at a rapid rate, this new technology, which controls the fusion process and uses fuels that are in abundant supply, warrants intensive investigation and development. Nevertheless the environmental risks associated with this technology are poorly understood, and these must be studied along with the development of the technology. This paper presents an analysis of the estimated concentrations in the environment of the main effluent expected to be emitted from the CTR's -- tritium. This isotope of hydrogen was first discovered by $\mathrm{Dr}$. Luis Alvarez and his colleagues in the late 1930's, and has since found wide application by many scientists in tracing components of the hydrologic cycle. The isotope undergoes a reaction favoring the formation of tritiated water vapor once released into the environment, and then behaves essentially as any other water vapor molecule.

The analysis of tritium concentrations in the hydrosphere expected from CTR power plants follows three phases, or time and space frames, based on an analysis by Machta, et al. (1973), of radioactive effluents released to the atmosphere from a proposed Liquid Metal Fast Breeder Reactor located in Morris, Illinois. Phase 1 studies ground-level atmospheric and surface water tritium concentrations within $50 \mathrm{Km}$ of the proposed CTR under normal 
operating conditions. Phase 2 studies regional ground-level atmospheric concentrations (up to $1000 \mathrm{Km}$ ) at any given time during the normal operation of the plant. Phase 3 examines the expected long term concentrations in the air and surface water supply throughout the northern hemisphere and globally during the normal operation of the plant. In addition, an analysis of surface water concentrations near the plant after an accidental large release of tritium during a rainfall episode is presented. Before this analysis is presented, however, it is appropriate to present a qualitative discussion of the behavior of tritium when released to the environment to set the stage for the rationale used in the computational procedures. 


\section{THE BEHAVIOR OF TRITIUM IN THE ENVIRONMENT}

\subsection{Emissions from Controlled Thermonuclear Reactors}

Several CTR technologies have been proposed, and each differs slightly in the fuel cycle, plasma confinement, and overall powerplant design. A summary of each design has been published by Young, et al. (1975). It is expected that, due to stringent plasma conditions, the fuels used in the initial plants will be deuterium and tritium. The reaction equation is given by:

$$
\mathrm{D}+\mathrm{T} \rightarrow{ }^{4} \mathrm{He}+\eta+17.6 \mathrm{Mev}
$$

The tritium fuel used in this reaction will need to be fabricated since adequate natural supplies do not exist. Tritium can be produced by bombarding lithium with neutrons, and indications are that blankets can be designed for $D-T$ fusion reactors which will breed tritium (Young, et al., 1975).

The major effluent from virtually all CTR designs will be tritium. Most designs use a liquid metal cooling blanket, which is expected to contain large quantities of tritium. Although many techniques have been proposed to contain the tritium, it is expected that large amounts will permeate through the heat exchanger and on through the heat transfer system. One proposed design uses a gas cooling system, and here large quantities of tritium are expected to penetrate the heat exchanger and enter the steam system, and from there be released into the environment through steam blowdowns. Although many tritium con- 
tainment systems are proposed for the reactor, they become economically unfeasible for the powerplant steam turbine system. Thus it is assumed that all tritium entering the steam generation system will be released into the environment through steam wastewater streams and ventilation air. These emissions are expected to be several orders of magnitude greater than with fission powerplants during normal operation, and can constitute a possible environmental hazard in an accident situation, particularly if a liquid metal fire breeches the reactor containment walls.

Tritium releases into the environment from nuclear power plants are expected to exceed the natural rate of tritium production by 1990 . A pressure water reactor can release up to 20 curies per year of tritium ( 9600 curies equals 1 gram of tritium), and it is expected that CTR's will emit several orders of magnitude more than this into the atmosphere and surface water.

\subsection{Transformation Processes in the Atmosphere}

Tritium can be released from a CTR either in its elemental form, such as HT, or as tritiated water vapor, HTO. The mass action equilibrium coefficient for the reaction:

$$
\mathrm{HT}+\mathrm{H}_{2} \mathrm{O} \underset{\mathrm{HTO}}{\rightarrow}+\mathrm{H}_{2}
$$

is approximately six, thus favoring the formation of tritiated water vapor. Jacobs (1968) cites many references which show that the predominant form of tritium in the atmosphere is in tritiated water 
vapor, and that tritium released to the atmosphere in its elemental form is quickly converted to tritiated water vapor. Therefore in this study it is assumed that all tritium released from a CTR into the environment is in the form of tritiated water vapor, HTO.

\subsection{Global Transport of Tritium and the Hydrometeorologic Cycle}

Once tritium is released into the environment and becomes tritiated water vapor its properties are essentjally the same as those of atmospheric water vapor. Thus tritium becomes a component of the hydrologic cycle, and behaves the same as water vapor in the hydrologic cycle. Jacobs (1968) notes through several references that the majority of tritium released in the troposphere is limited to the general latitude of release, although some lateral mixing is to be expected. Almost half of all the tritium released into the stratosphere during the nuclear bomb tests was deposited in the northern hemispherical mid-1atitude belts, and since these are the latitudes in which most of the CTR activity is expected to take place, these are the latitudes in which the highest air and surface water concentrations of tritium are expected to occur.

The removal of tritium from the atmosphere, as noted in the following section, occurs primarily through the precipitation process, although near the point of release some tritiated water vapor can be diffused to the ground and taken up directly by vegetation. Once deposited the tritium can infiltrate into the groundwater, remain as part of the surface runoff and storage, assimilated into plants, 
or transpired and evaporated back into the atmosphere. Because of its close association with the hydrologic cycle it has served as a useful isotope in determining the characteristics of various watersheds. 


\section{SCAVENGING OF TRITIUM BY PRECIPITATION}

\subsection{Theory of Scavenging}

The process of removal of material emitted to the atmosphere by precipitation is traditionally investigated in terms of below-cloud scavenging in the form,

$$
Q(t)=Q_{0} \exp (-\Lambda t)
$$

where:

$$
\begin{aligned}
Q(t)= & \text { amount of emitted source material remaining } \\
& \text { after some time } t(\mathrm{ci} / \mathrm{yr}) \\
Q_{0}= & \text { source term (ci/yr) } \\
\Lambda \quad= & \text { constant scavenging coefficient for the } \\
& \text { emitted material }\left(\mathrm{sec}^{-1}\right) \\
t \quad= & \text { time period (sec) }
\end{aligned}
$$

This approach has been used for trace quantities of gases assuming that the gases are perfectly soluble (Engelmann, 1965). However it has been shown that the solubility of gases is important (Hales, 1972a). Since $\Lambda$ is not necessarily constant and can vary considerably in time (Dana, et al., 1972; Hales, 1972a) it is not useful to utilize this definition of washout for gases. Assuming a steady state condition with non-interacting drops and no chemical reactions, the rate of change of liquid-phase concentration with height $z$ can be expressed as 


$$
\frac{d c}{d z}=\frac{3 K y}{V_{t} r}\left(x-H^{\prime} C\right)
$$

where:

$$
\begin{aligned}
& \mathrm{K}_{\mathrm{y}}=\text { overall mass transfer coefficient } \\
& \text { (mass }-\mathrm{cm}^{-2}-\mathrm{sec}^{-1} \text { ) } \\
& V_{t}=\text { terminal velocity of fall of the raindrop } \\
& \text { of radius } R \text {, where downward is negative }\left(\mathrm{cm}-\mathrm{sec}^{-1}\right) \\
& X=10 c a l \text { atmospheric gas-phase pollutant concen- } \\
& \text { tration (mass }-\mathrm{cm}^{-3} \text { ) } \\
& \mathrm{H}^{\prime} \text { = solubility (Henry's law) factor (in units } \\
& \text { appropriate to those of }(\text { and } x \text { ) } \\
& \mathrm{C}=\text { gas-phase concentration in the raindrop } \\
& \text { (mass }-\mathrm{cm}^{-3} \text { ) } \\
& r \text { = raindrop radius }(\mathrm{cm})
\end{aligned}
$$

If perfect solubility of the material emitted to the atmosphere is assumed $\left(H^{\prime}=0\right)$, it can be shown that the integration of equation (4) leads to traditional forms for $\Lambda$.

For gases in general $H^{\prime} \neq 0$, and there is a reluctance to being scavenged; in regions where the second term of equation (4) predominates, the gas can desorb from the drop. Equation (4) can be integrated analytically for the case where $H^{\prime}=$ constant and the rainfall is vertical (Hales, 1972a, 1972b) or numerically for $H^{\prime}=H^{\prime}(C, x)$ (Dana, et al., 1973). 
Computer programs have been developed to perform this calculation. These programs fall under two categories - linear and non-linear models. The linear model can be effectively used for HTO due to the nature of the solubility of HTO, which like $\mathrm{H}_{2} \mathrm{O}$ is a function of temperature only (Hales, 1972b). Integration of equation (4) for HTO leads to ground-level concentrations in the rainfall which depend on several variables: plume parameters, downwind distance $x$ (i.e., time for a constant wind speed $u=x / t$ ), temperature, mass transfer, diffusion coefficients for gas phase transfer, and $H^{\prime}$ for liquid phase transfer. Using different variable values, plume centerline concentrations of the raindrops, $\mathrm{C}_{\mathrm{cl}}$, effective scavenging coefficients $k$, and source strengths $Q(x)$ have been obtained (Figures 3.1 and 3.2). The input conditions are listed in Table 3.1.

The values of $k$ were computed by taking advantage of the fact that for linearly soluble gases, the concentration in the raindrops off the centerline $C(y)$ is

$$
C(y)=C_{c l} \exp \left(-y^{2} / 2 \sigma_{y}^{2}\right)
$$

where $\sigma_{y}$ is the horizontal dispersion parameter and $y$ is the distance from the centerline. The cross-plume integrated flux, or "scavenging rate", $\bar{W}$, is :

$$
\bar{W}=\int_{-\infty}^{+\infty} C(y) J d y=J C_{c l} \sqrt{2 \pi \sigma_{y}} U
$$


TABLE 3.1

Input Conditions Used in EPAEC Linear Mode1

Temperature

Source Height

Rainfall Rate

Wind Speed

Plume

Mass Transfer Regime

Raindrop Spectrum
$273,303 \mathrm{~K}$

$30,100,000 \mathrm{~m}$

$1,5 \mathrm{~mm} / \mathrm{hr}$

$500 \mathrm{~cm} / \mathrm{sec}$

Pasquil1-Gifford with appropriate sigmas (Smith, et al., 1966)

Gas-Phase Controlled (Well Mixed Drop)*

Lognormal (typical frontal rain)

*There is not much difference between gas-phase controlled and stagnant drop transfer for HTO (stagnant drop less in magnitude). Experimental work (Friedman, et al., 1962; Booker, 1965) has shown HTO to behave primarily in accordance with gas-phase controlled behavior. 


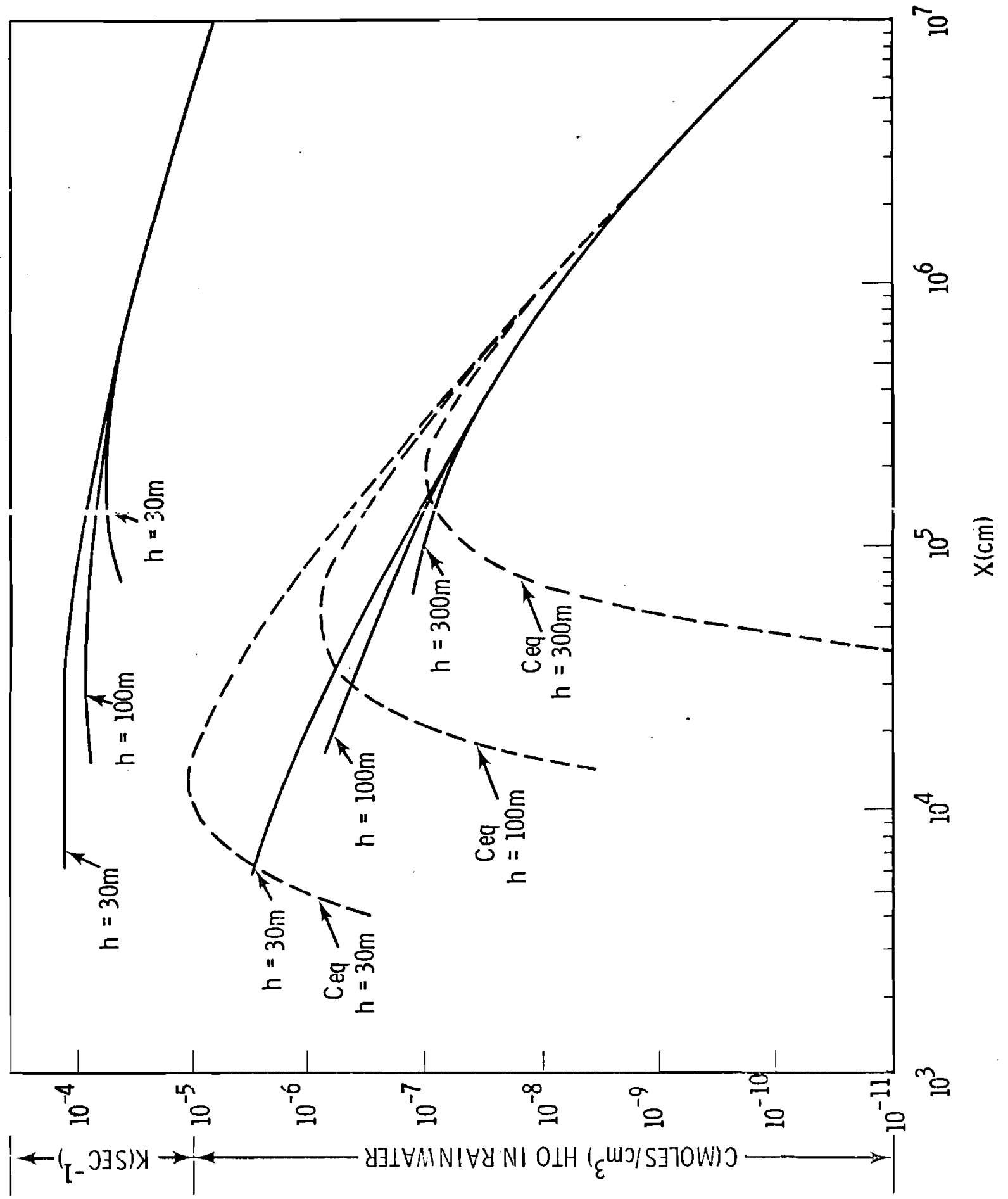

Figure 3.1 Amount of Tritium in Rainwater for Equilibrium and Non-equilibrium Conditions as a Function of Distance. 


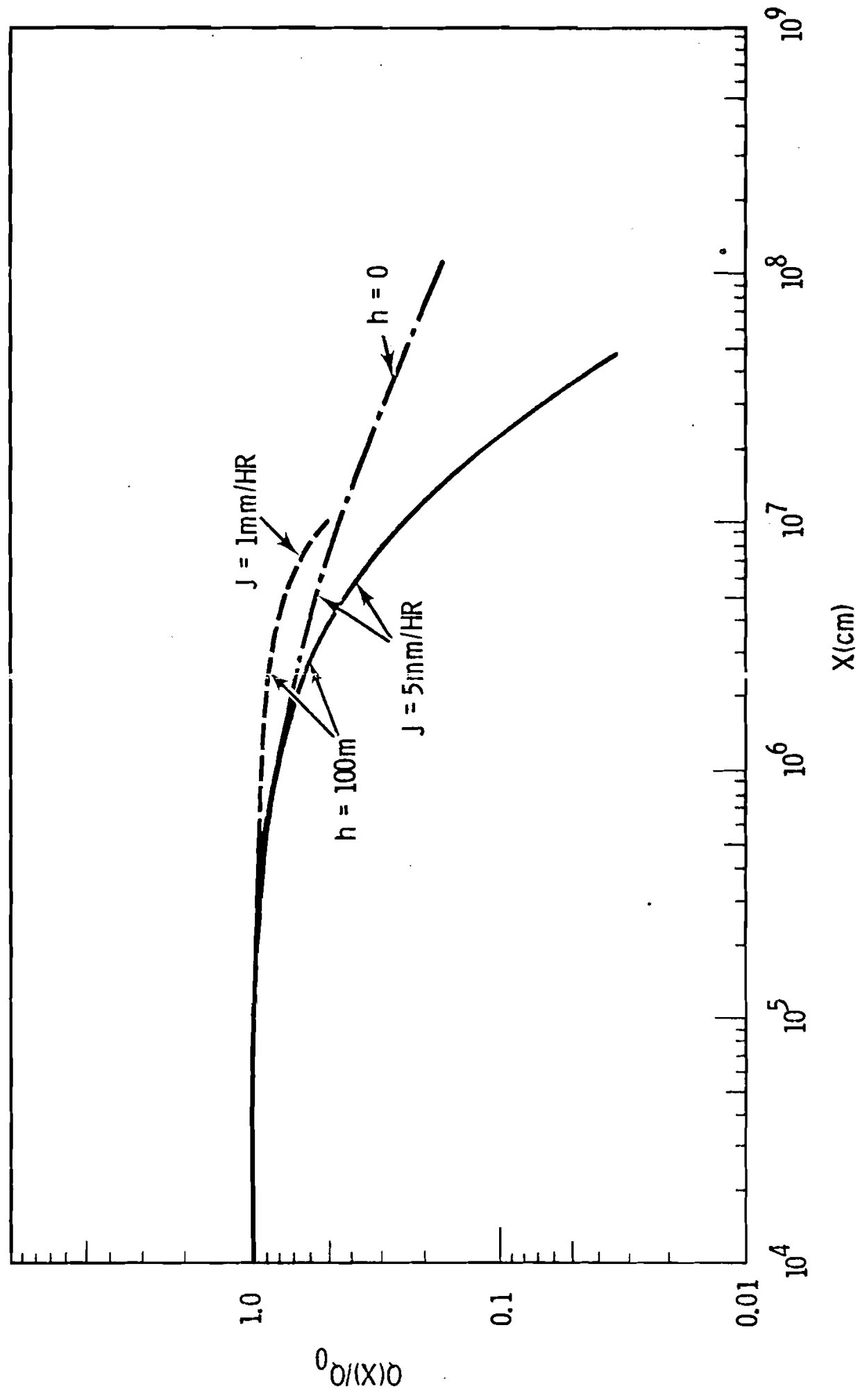

Figure 3.2 $Q(x) / Q_{0}$ as a Function of Release Height $(h)$, Rainfall Rate $(\mathrm{J})$, and Downwind Distance $(\mathrm{x})$. 
where $J$ is the rainfali rate. The effective scavenging coefficient, $k$, is then

$$
k=\frac{\bar{W}}{Q}=\frac{\mathrm{JC}_{\mathrm{cl}} \sqrt{2 \pi \sigma} \overline{\mathrm{U}}}{Q} .
$$

Since the calculated values of $k$ at each $x$ were sufficiently high to deplete the plume significantly during moderate downwind travel times, $\mathrm{Q}$ was reduced numerically by

$$
Q(x)=Q_{0} \exp \left(-k^{\prime} x / \bar{U}\right)
$$

where $k^{\prime}$ is the average value of $k$ calculated at the location $x$ and the previous location, and $\bar{U}$ is the mean wind speed. The curves for $Q(x)$ in Figure 3.2 are approximate due to neglect of the near-source region. However, it is evident that depletion of HTO by rainfall within about 10 stack heights downwind is negligible.

\subsection{Below-Cloud Equilibrium Scavenging}

In Figure 3.1, $\mathrm{C}_{\mathrm{eq}}$ represents the raindrop concentration which would result if the HTO in the rain is in equilibrium with groundlevel air concentration:

$$
c_{e q}=\frac{X_{g l}}{H^{\top}}
$$

Since $H^{\prime}$ is a constant for a given $T, C_{e q}(x)$ exactly follows the wellknown Gaussian behavior of $x$. It is clear from Figure 3.1 that $C \sim C_{\text {eq }}$ beyond $x \simeq 10 \mathrm{~km}$, for all reasonable values of $h$. The effective equilibrium scavenging coefficient is 


$$
\mathrm{k}_{\mathrm{eq}}=\frac{\mathrm{JC}}{\int_{0}^{\infty} \mathrm{X}_{\mathrm{d} z}}=\frac{\mathrm{J}}{\mathrm{H}^{\star}} \quad \frac{\sqrt{2}}{\pi} \frac{1}{\sigma_{z}} \exp \left(-\frac{\mathrm{h}^{2}}{2 \sigma_{z}^{2}}\right)
$$

where $\mathrm{H}^{*}$ is a Henry's law factor for $\chi$ and $\mathrm{C}$ is written in units of mass $/ \mathrm{cm}^{3}$. The exponential term is effectively unity for reasonable values of $h$ and plume parameters beyond $x \simeq 10 \mathrm{~km}$.

An alternate expression for $k_{e q}$ at great distances from the source can be obtained by assuming that

$$
\int_{0}^{\infty} x_{d x}=x_{g 1} L
$$

where $x_{g 1}$ is a constant and $L$ is an effective thickness of the polluted layer in the $z$ direction. It is also assumed that $x=x_{g l}$ at all levels. With these assumptions $\mathrm{k}_{\mathrm{eq}}$ is equal to $\mathrm{J} /\left(\mathrm{H}^{*} \mathrm{~L}\right)$. If it is further assumed that $H^{*}=\rho_{a} / \rho_{w}$, where $\rho_{a}$ is the absolute humidity of $\mathrm{H}_{2} \mathrm{O}$ and $\rho_{w}$ the density of water, and $\bar{R}$ is the rain flux in grams $>\mathrm{cm}^{-2}-\sec ^{-1}$, then

$$
\mathrm{k}_{\text {eq }}=\frac{\bar{R}}{\rho_{\mathrm{a}} \mathrm{L}} \text { and } J=\frac{\bar{R}}{\rho_{\mathrm{w}}} \text {. }
$$

This form of $\mathrm{k}_{\mathrm{eq}}$, reported by and Dickerson and Crawford, (1972), is similar to equation (10) for ground-level releases as long as distances from the source are considerable. 
The assumption of $\mathrm{H}^{*}{ }_{\mathrm{HTO}}={ }^{\mathrm{H}^{*}} \mathrm{H}_{2} \mathrm{O}$ is probably quite good, except that it must be recognized that the absolute humidity $\rho_{a}$ for water vapor and HTO is a function of temperature. A plot of $\mathrm{H}^{*}$ as a function of temperature is given in Figure 3.3 .

\subsection{In-Cloud Scavenging}

Due to the low fall speeds and small size of cloud droplets it can be assumed that these which exist in a plume will have HTO concentrations which are in equilibrium with the local air concentration of HTO. Therefore, in-cloud scavenging is characterized primarily by the pickup of cloud droplets by raindrops. Thus, an additional term to equation (4) is added:

$$
\left.\frac{\mathrm{dc}}{\mathrm{d} z}\right|_{\mathrm{cloud} \text { drops }}=-\frac{3 \varepsilon(\mathrm{r})(\mathrm{LWC}) \mathrm{x}}{4 \mathrm{r} \mathrm{H}^{\top} \rho_{w}}
$$

where (LWC) is the liquid water content of the fog and $\varepsilon$ is a collection efficiency which defines the mass transfer of cloud drops to raindrops. By comparison of the cloud droplet term to the gas scavenging term, a criterion for the importance of cloud drop scavenging can be developed. For the cloud drop component to be insignificant :

$$
\text { Ratio }=\frac{4 \mathrm{~K}_{y} \mathrm{H}^{\prime} \rho_{W}}{\varepsilon(\mathrm{LWC}) \mathrm{V}_{t}}>1
$$

For HTO, assuming gas-phase transfer, $V_{t}=500 \mathrm{~cm} / \mathrm{sec}, \mathrm{T}=283^{\circ} \mathrm{K}$, and $\varepsilon=1$, the values of the ratio and the fraction of the concentration 


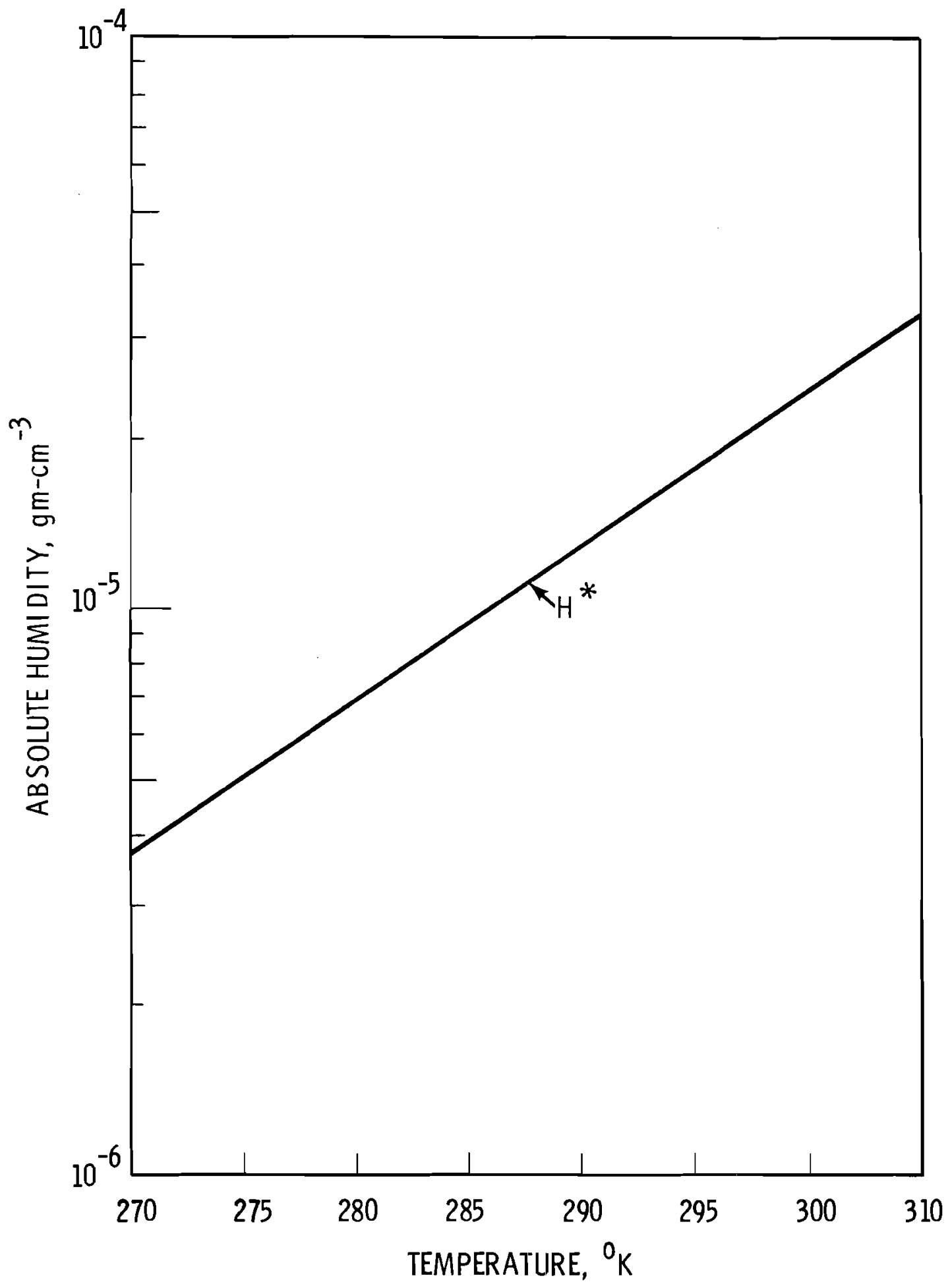

Figure 3.3 Henry's Constant $\left(\mathrm{H}^{*}\right)$ as a Function of Temperature. 
contributed by cloud drop scavenging can be estimated. Some are listed in Table 3.2.

TABLE 3.2

Values of Ratio and Fraction of Raindrop Concentration of HTO Contributed by Cloud-Drop Scavenging

$\begin{array}{lcc}\frac{(L W C)}{0.1 \mathrm{~g} / \mathrm{m}^{3}} & \frac{\text { Ratio }}{4} & \frac{\text { Fraction }}{.20} \\ 0.5 \mathrm{~g} / \mathrm{m}^{3} & 1.25 & .44 \\ 1.0 \mathrm{~g} / \mathrm{m}^{3} & 0.4 & .71\end{array}$

For rain which forms from tritiated water vapor by condensation, it is probably safe to assume that $C=C_{\text {eq }}$ because of the time involved in the process, as long as $x>10 \mathrm{~km}$ or so. For the case of the convective shower acting right at the source point, it is probably safe to assume that the efficiency with which the shower removes water will also apply to HTO. A very heavy rainfall rate will also deplete the plume quite effectively by washout alone, as Figure 3.2 indicates.

\subsection{Alternatives and Limitations on Models}

The linear model is not very accurate for distances less than about one stack height downwind, due to the neglect of the angle of raindrop trajectories. The depletion within this region will be very slight, although the value of $k$ may be quite high in a small space 
between where desorption predominates (i.e., with the plume well above the ground, so that $\mathrm{C}_{\mathrm{eq}}$ at ground-level is very low) and where the concentration begins to decrease toward $\mathrm{C}_{\mathrm{eq}}$.

The curves of Figures 3.1 and 3.2 can be used to estimate rainwater concentrations or scavenging coefficients for other input variables. The concentration $C_{c l}$ is directly proportional to $Q(x)$ and inversely proportional to $\mathrm{u} ; \mathrm{k}$ is directly proportional to $\mathrm{J}$. Therefore, concentrations for any and all values of $Q(x), J$ and $u$ can be predicted from one curve. To account for depletion, however, $Q(x)$ must be calculated for each point $x$ based on the scavenging "history" of the plume. The scavenging coefficient may be determined at any $x$ since it is not a function of the source term. 


\section{ANALYSIS OF TRITIUM CONCENTRATIONS IN THE HYDROSPHERE}

\subsection{Phase 1: Estimated Average Ground-Level Concentrations Near the Plant}

The technique for computing average annual ground-level concentrations of tritium within $50 \mathrm{~km}$ of a CTR power plant involves evaluation of the relation:

$$
x_{a} / Q=\left\{\frac{1}{\pi \sigma_{y} \sigma_{z} \bar{u}} \exp \left(-y^{2} / 2 \sigma_{y}^{2}\right)\right\} \exp \left[-k_{e q}(x / \bar{u})\right]
$$

where:

$$
\begin{aligned}
& x_{a}=\text { atmospheric tritium concentration }\left(\mathrm{Ci}-\mathrm{m}^{-3}\right) \\
& Q=\text { source term to the atmosphere }\left(\text { ci-year }{ }^{-1}\right) \\
& \sigma_{y}=0.5 t=\text { horizontal standard deviation of the } \\
& \text { plume (meters) } \\
& \sigma_{z}=2 \mathrm{~K}_{z}(\mathrm{x} / \overline{\mathrm{u}})^{1 / 2}=\text { vertical standard deviation of the } \\
& \text { plume (meters) } \\
& t=\text { plume travel time }(\mathrm{sec}) \\
& \mathrm{K}_{z}=\text { vertical diffusion coefficient }=5 \mathrm{~m}^{2}-\mathrm{sec}^{-1} \\
& \overline{\mathrm{u}}=\text { mean wind speed through the layer } 300 \mathrm{~m} \text { to } 2000 \mathrm{~m} \\
& \text { above ground } \\
& k_{e q}=\text { equilibrium scavenging coefficient } \\
& x=\text { downwind distance from the source (meters) } \\
& y=\text { plume crosswind distance (meters) }
\end{aligned}
$$

The term in the curly brackets in equation (15) was evaluated by Heffter, et al., (1975) for the LMFBR environmental analysis using a 
climatology of wind trajectories near Morris, Illinois. In this analysis it is also assumed that the CTR will be located near Morris, Illinois.

The second exponential term in equation (15) represents the depletion of the plume due to scavenging of tritium by precipitation. Under equilibrium conditions, where the in-cloud and below-cloud tritium concentrations are equal, and where the height of the release is at ground-level, the equilibrium scavenging coefficient, keq, is obtained from equation (10):

$$
\mathrm{k}_{\mathrm{eq}}=\frac{\mathrm{J}}{\mathrm{H}^{\star}}\left(\frac{2}{\pi}\right)^{1 / 2} \frac{1}{\sigma_{\mathrm{z}}^{\prime}}
$$

where

$$
\begin{aligned}
\sigma_{z}^{\prime}=\text { Smith-Singer dispersion coefficient } & =0.63 \mathrm{x}^{0.86}, x \leq 4.4 \mathrm{~km} \\
& =859 \mathrm{~m}, \mathrm{x}>4.4 \mathrm{~km}
\end{aligned}
$$

By assuming equilibrium conditions below the precipitating cloud, the values of $\mathrm{k}_{\mathrm{eq}}$ are within $10 \%$ of the $\mathrm{k}_{\mathrm{eq}}$ values determined by Dickerson and Crawford (1972) for use in the LMFBR analysis at Morris, Illinois.

The results of the ground-level atmospheric tritium concentration estimates are shown in Figure 4.1 for Phase 1. The concentrations in this figure have been normalized to a 1 ci-year $^{-1}$ release. To determine estimated concentration for any source rate the normalized concentrations in the figure must be multiplied by that source rate. 


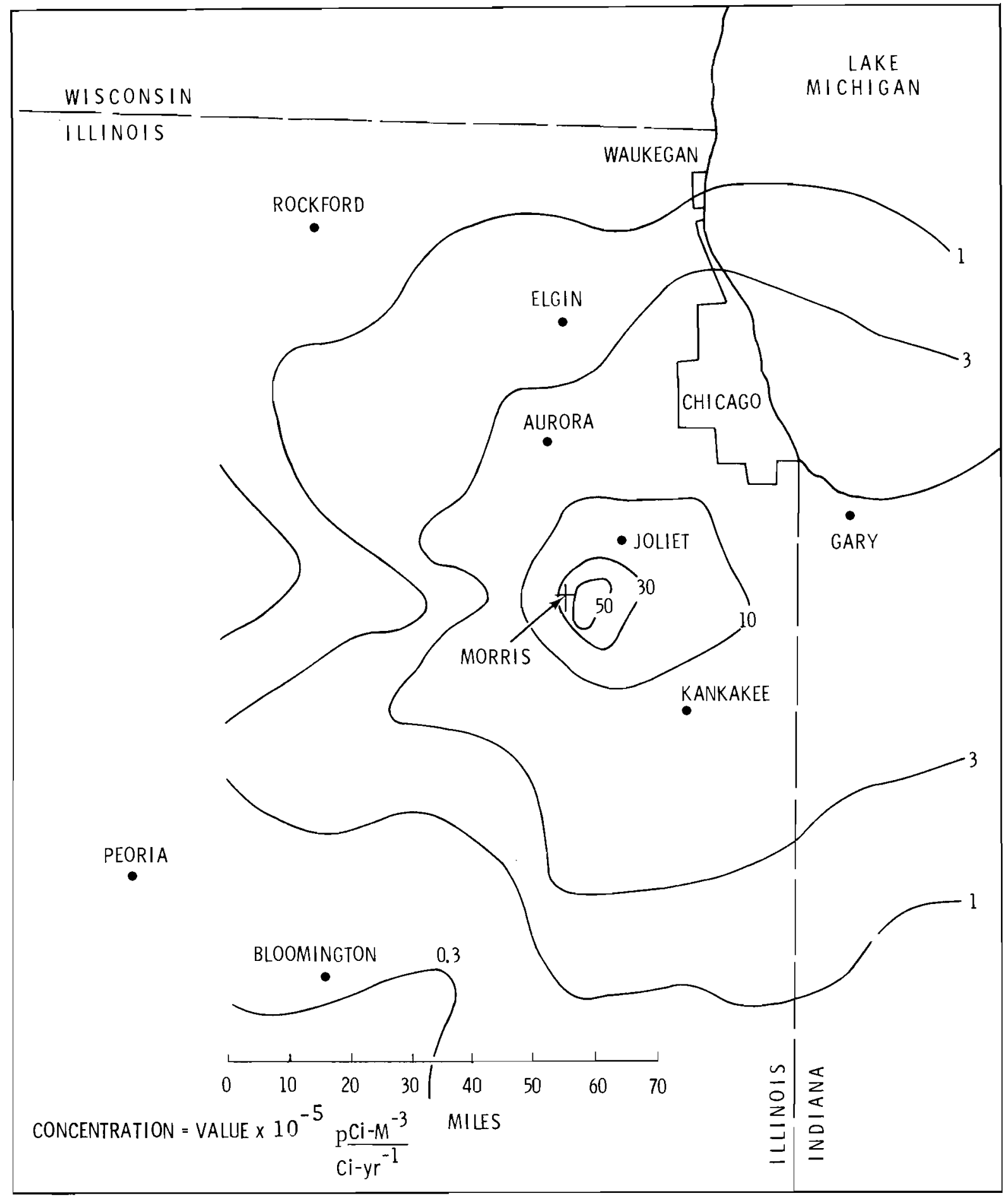

Figure 4.1 Ground-Level Air Concentration Values of Tritium for an Area Near Morris, Illinois. 
4.2 Phase 2: Estimated Average Ground-Level Concentrations in the Eastern Half of the United States

This phase of the analysis deals with plume trajectories from the proposed CTR plant over a travel time of several days, or distances up to 1000 kilometers. Heffter, et al., (1975) treat this problem in the same fashion as in Phase 1, utilizing a climatology of air trajectories over the eastern United States and then applying equation (15). The results of the regional ground-level tritium concentration estimates are shown in Figure 4.2.

\subsection{Average Surface Water Tritium Concentrations near a CTR Plant}

The average annual surface water tritium concentrations, $x_{g}$, are determined from:

$$
x_{g}=c\left\{\frac{1-\exp \left[-k_{e q}(x / \bar{u}]\right.}{A W}\right\}
$$

where:

$$
\begin{aligned}
W= & \text { average annual depth of the surface or groundwater } \\
& \text { mixing layer, (m-year } \left.{ }^{-1}\right) \\
A= & \text { area of precipitation }\left(\mathrm{m}^{2}\right)
\end{aligned}
$$

Since this analysis is intended to provide conservative estimates of tritium concentrations that would show the maximum expected impacts for normal operation and accidental releases, the value of $W$ was assumed to be determined from the mean annual net rainfall: 


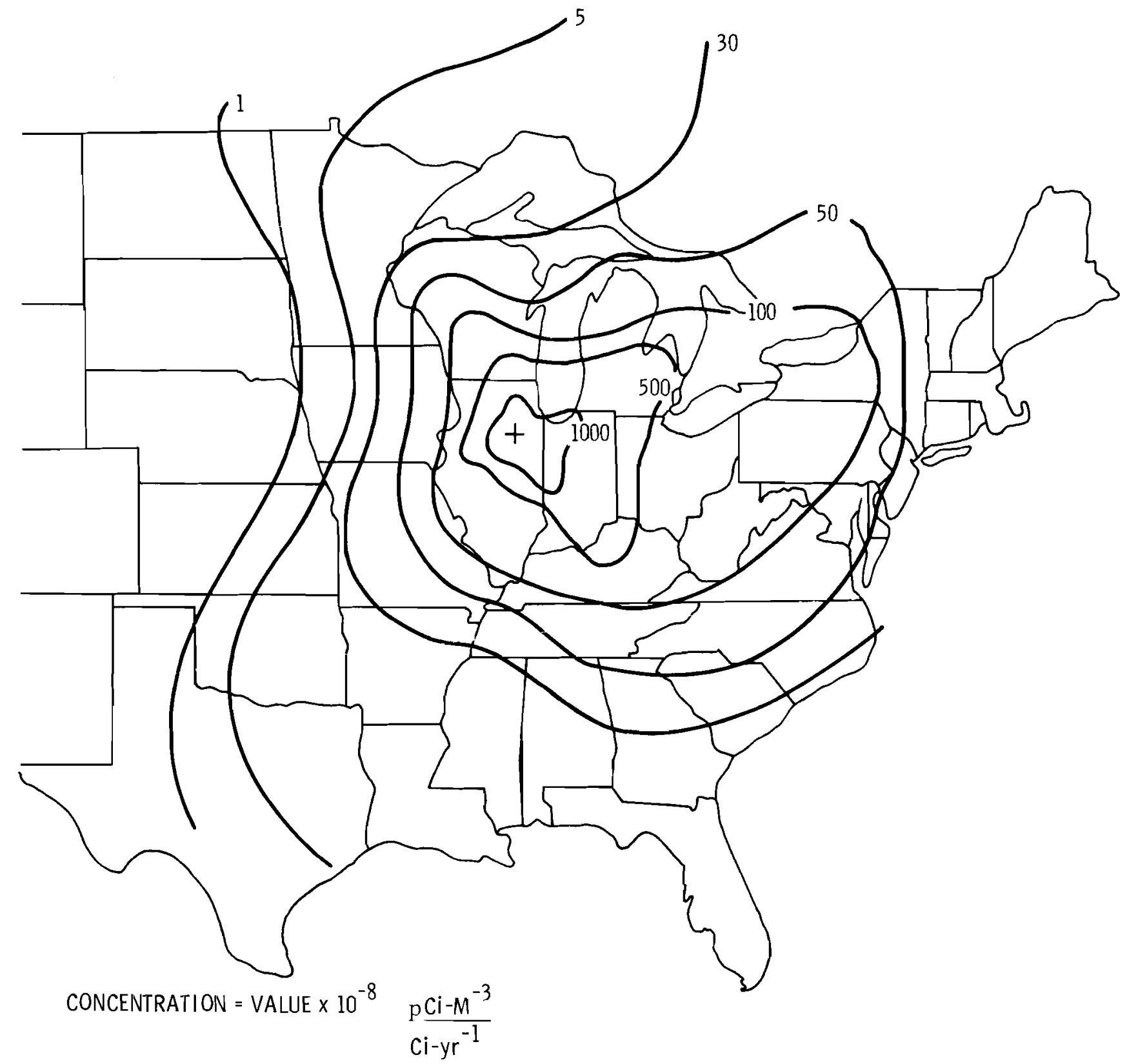

Figure 4.2 Ground-Level Air Concentration Values of Tritium for the Eastern United States. 


$$
\frac{\mathrm{AW}}{\mathrm{year}}=\mathrm{P}-\mathrm{E}
$$

where:

$$
\begin{aligned}
& P=\text { amount of precipitation }\left(\mathrm{m}^{3} \text {-year }{ }^{-1}\right) \\
& E=\text { amount of evaporation }\left(\mathrm{m}^{3}\right. \text {-year }
\end{aligned}
$$

In other words, there is no groundwater reservoir into which tritium would be mixed after tritiated rainfall percolates through the ground. For Morris, Illinois the annual rainfall averages 0.93 $0.93 \mathrm{~m}^{-\mathrm{yr}^{-1}}$, and evaporation (determined from Sellers, 1965) is $0.56 \mathrm{~m}^{-y_{e a r}}{ }^{-1}$. Thus the mean annual runoff is $0.37 \mathrm{~m}-y e a r^{-1}$, and $W=0.37$ meters.

Equation (17) shows that estimates of surface water concentrations of tritium are made by determining the amount of the source term that is depleted by washout processes. Thus, estimates of surface water concentrations were made for each concentric areal ring around a CTR located in Morris, Illinois from the relation:

$$
\left.x_{g}\right|_{x=j-i}=Q\left[\left(1-f_{x=j}\right)-\left(1-f_{x=i}\right)\right]
$$

where:

$$
\begin{aligned}
\hat{\mathrm{I}}= & \exp \left[-\mathrm{k}_{\text {eq }}\left(\frac{\mathrm{x}}{\mathrm{u}}\right)\right] \\
\mathrm{i}= & \text { radial distance to inner circumference of a } \\
& \text { concentric areal ring } \\
j= & \text { radial distance to outer circumference of a } \\
& \text { concentric areal ring }
\end{aligned}
$$


This technique has the disadvantage of assuming that all precipitation systems are distributed equally around a CTR, along with the distribution of HTO. This assumption obviously becomes poorer at greater distances from the source. In particular, it is obvious that the tritium washed out by precipitation systems will always be downwind of the CTR, which in Morris, Illinois will always be in a prefered section, and not uniformly distributed around the p1ant. For this reason the analysis is limited to distances up to $1000 \mathrm{~km}$, using the hydrological conditions for Morris.

The result of the surface water tritium concentrations using an iteration of equation (19) and (17) are shown in Table 4.1. The results provided are normalized concentrations. Figure 4.3 shows the variation of surface water concentrations with distance from the source using the hydrologic conditions at Morris. The value of $\sigma_{z}$ ' during precipitation episodes were obtained from the LMFBR analysis. For Morris, the value of $\sigma_{z}{ }^{\prime}$ increases to a distance of $4.4 \mathrm{~km}$, and is constant beyond that point. Figure 4.3 reflects this change in the vertical dispersion. It is evident that the smaller dispersion near the plant acts to increase surface water concentrations by as much as two orders of magnitude above what would have been estimated from a constant dispersion. 
TABLE 4.1

$\frac{\text { Surface Water Tritium Concentrations }\left(x_{g}\right)}{\text { For Various Distances from the Source }}$

Radia1 Distance $(\mathrm{Km})$ $\triangle \mathrm{f}^{*}$ Area
$\left(\mathrm{m}^{2}\right)$ .0317 $.785 \times 10^{10}$ .0307

$2.36 \times 10^{10}$

$x_{\mathrm{g}} / \mathrm{Q}$

$$
0-50
$$

.0298

$3.93 \times 10^{10}$

$\left(\frac{\mathrm{pCi}-\ell^{-1}}{c i-y r^{-1}}\right)$

50-100

.0298

$150-200$

.0287

$5.50 \times 10^{10}$

$10.9 \times 10^{-3}$

$100-150$

.0279

$7.06 \times 10^{10}$

3.52

$200-250$

.0270

$8.64 \times 10^{10}$

2.05

$250-300$

.0997

$5.02 \times 10^{11}$ .844

$300-500$

.1995

$2.36 \times 10^{12}$ .537

$500-1000$

.228

*Note: $\quad \Delta f=\left(1-f_{\chi=j}\right)-\left(1-f_{\chi=i}\right) \quad$ (See equation (19) 


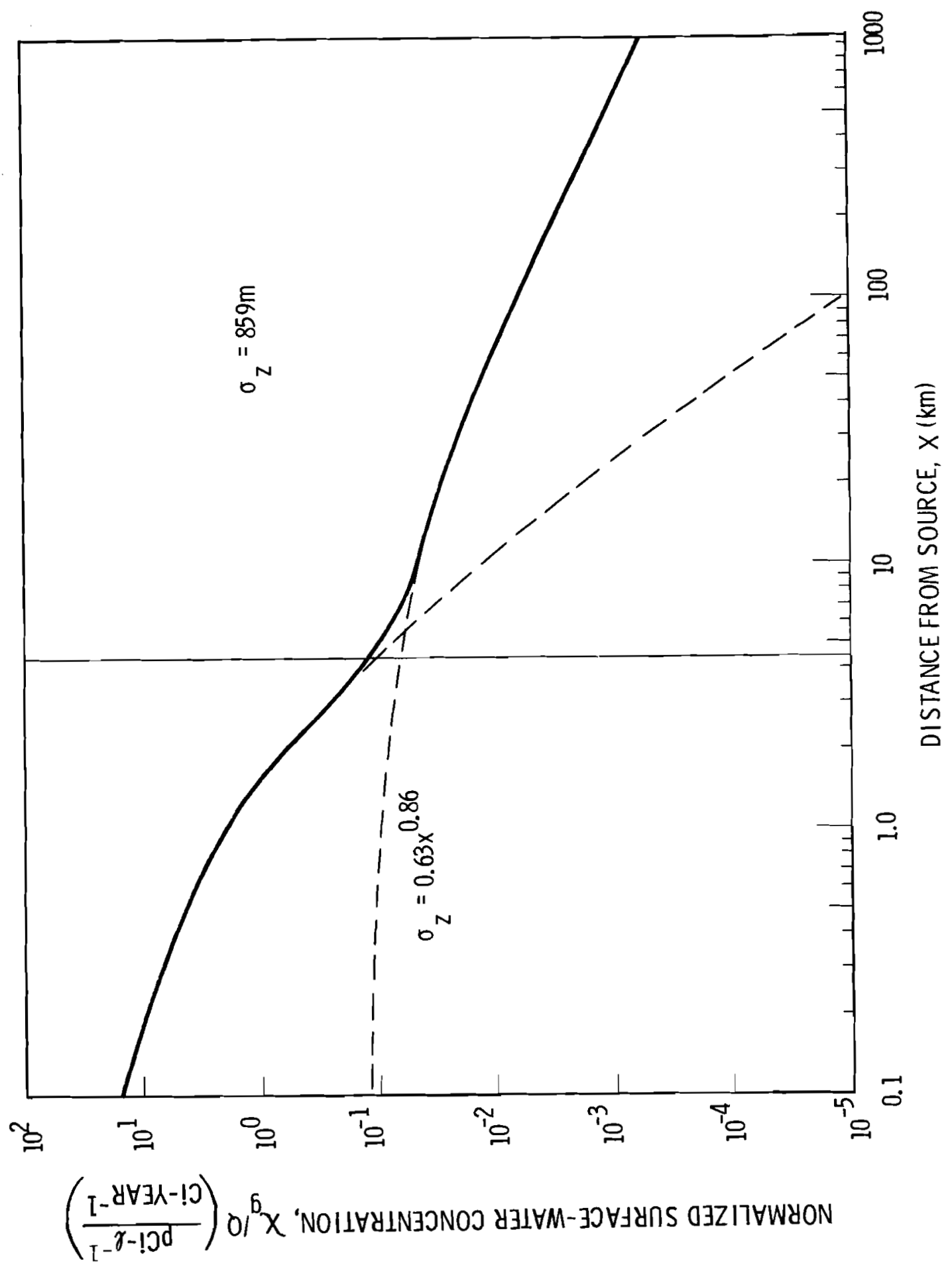

Figure 4.3 Normalized Surface Water Concentration $\left(\mathrm{Xg}_{\mathrm{g}} / \mathrm{Q}\right)$ as a Function of Distance $(\mathrm{x})$. 
4.4 Phase 3: Estimated Latitudinal and Global Average Atmospheric and Surface Water Tritium Concentrations

A technique was developed to analyze the estimated concentrations of tritium in the atmosphere and surface water supplies in the northern hemisphere based on a continuous normal operation of CTR plants distributed throughout the $30^{\circ}-50^{\circ} \mathrm{N}$ latitude belt. The analysis technique is based on the procedure presented by Libby (1963) with modifications to account for sources near ground-level and for the transport of hydrologic components across latitude belts. The technique is essentially a "box model" approach which assumes that the tritium follows the hydrologic cycle, and represents the simultaneous solution of atmospheric and surface water tritium concentrations to establish the maximum values.

The balance equation for atmospheric tritium in any latitude belt can be developed from an examination of Figure 4.4 and is written

$$
\frac{A}{\rho_{a}}-\frac{d(w}{d t}=\left(Q_{a}+E x_{g}+I_{\text {in }} x_{a_{o}}\right)-\left\{P x_{a}+I_{\text {out }} x_{a}+(A w / 18) x_{a}\right\}
$$

where:

$$
\begin{aligned}
& \mathrm{Q}_{\mathrm{a}}=\text { source of tritium to the atmosphere, distributed } \\
& \text { throughout the latitude belt }\left(\mathrm{Ci}-\mathrm{yr}^{-1}\right) \\
& \begin{aligned}
x_{a_{0}}= & \text { concentration of atmospheric tritium entering the } \\
& \text { latitudinal boundary }\left(\mathrm{c} i-\mathrm{m}^{-3}\right)
\end{aligned} \\
& \mathrm{P}=\text { latitude-averaged precipitation }\left(\mathrm{m}^{3}-\mathrm{yr}^{-1}\right)
\end{aligned}
$$




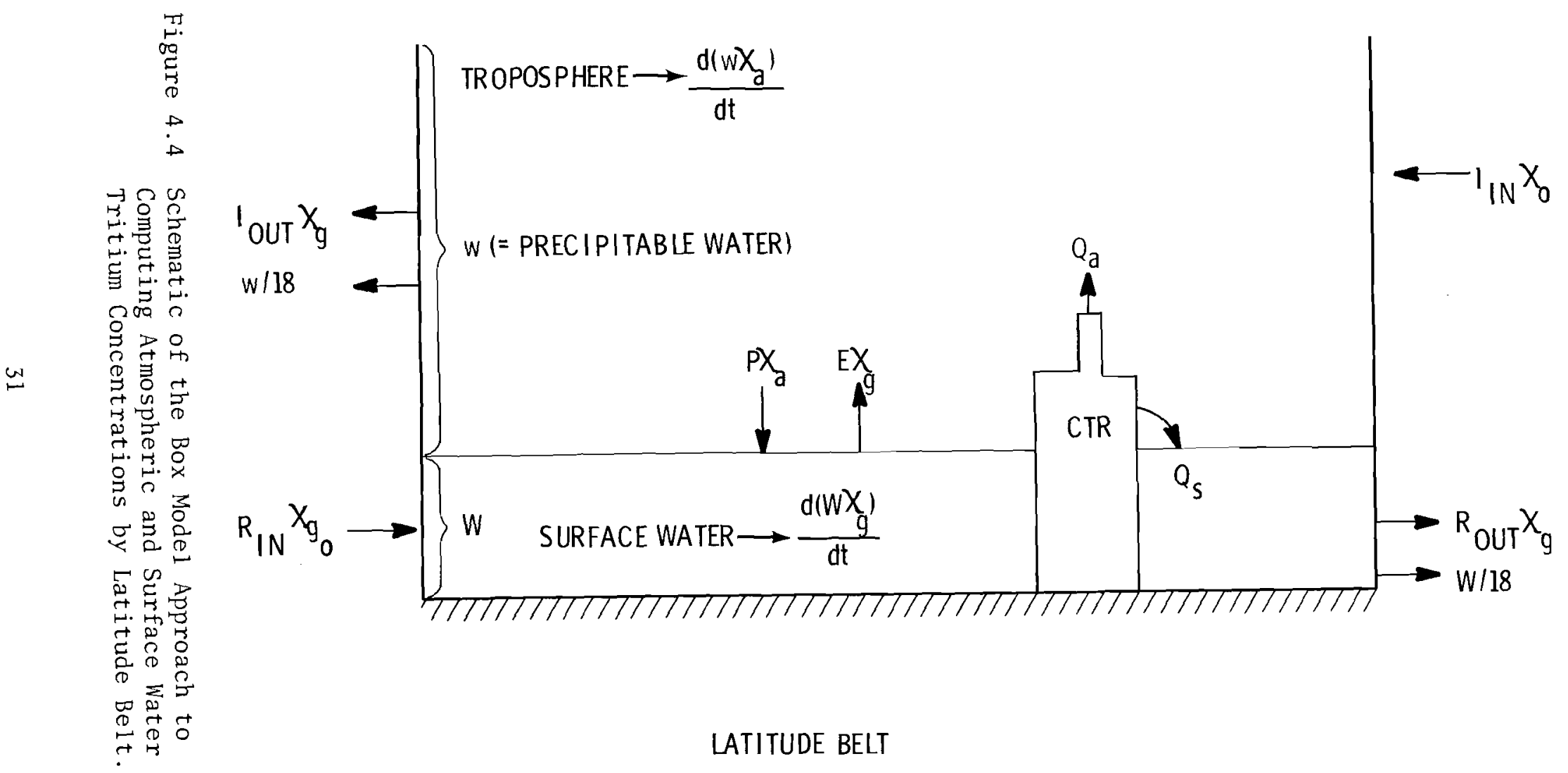


$E=1$ atitude-averaged evaporation $\left(m^{3}-y r^{-1}\right)$

$w=$ depth of atmospheric water (i.e., precipitable water), $m$

$(\mathrm{w} / 18) x_{\mathrm{a}}=$ average radioactive 1 ife of tritium in atmosphere

$$
\begin{aligned}
\rho_{a}= & \text { absolute humidity } \frac{\mathrm{m}^{3} \mathrm{H}_{2} \mathrm{O}}{\mathrm{m}^{3} \mathrm{Air}} \\
\mathrm{A}= & \text { area of the latitude belt }\left(\mathrm{m}^{2}\right) \\
I_{\text {in }}= & \text { influx of water vapor across the latitudinal boundary } \\
& \left(\mathrm{m}^{3} \text {-year }{ }^{-1}\right) \\
I_{\text {out }}= & \text { outflux of water vapor acorss the latitudinal boundary }^{3} \\
& \left(\mathrm{~m}^{3}\right. \text {-year }
\end{aligned}
$$

Likewise, the balance equation for surface water tritium is written

$$
A \frac{d\left(W x_{g}\right)}{d t}=Q_{s}+P x_{a}+R_{\text {in }} x_{g_{0}}-\left\{E x_{g}+R_{o u t} x_{g}+(A W / 18) x_{g}\right\}
$$

where:

$$
\begin{aligned}
Q_{S}= & \text { source of tritium to the surface water, distributed } \\
& \text { throughout the latitude belt }\left(\mathrm{ci-m}-\mathrm{m}^{-3}-\mathrm{yr}^{-1}\right) \\
x_{\mathrm{g}_{0}=} & \text { concentration of surface water tritium entering the } \\
& \text { latitudinal boundary } \\
W= & \text { depth of readily-mixed groundwater, meters }
\end{aligned}
$$

$(W / 18) x_{g}=$ average radioactive 1 ife of tritium in the surface water $\mathrm{R}_{\text {in }}=$ surface run-off into the latitudinal "box" $\left(\mathrm{m}^{3}-\mathrm{yr}^{-1}\right)$ $R_{\text {out }}=$ surface run-off out of the latitudinal "box" $\left(\mathrm{m}^{3}-\mathrm{yr}^{-1}\right)$

Over a long period of time (for the atmosphere a period of several weeks and for the groundwater a period of several years) each of these balance equations has the solution: 


$$
\begin{aligned}
& \frac{x_{a_{\max }}}{\rho_{a}}=\frac{Q_{a}+E x_{g}+I_{\text {in }} x_{a_{o}}}{P+I_{\text {out }}+A w / 18} \\
& x_{g_{\max }}=\frac{Q_{s}+P x_{a}+R_{\text {in }} x_{g_{o}}}{E+R_{\text {out }}+A w / 18}
\end{aligned}
$$

If it is now assumed that:

$$
\begin{aligned}
& \mathrm{R}_{\text {out }}=\mathrm{R}_{\text {in }}+(P-E) \\
& \mathrm{I}_{\text {out }}=\mathrm{I}_{\text {in }}-(P-E) \\
& \mathrm{Q}_{\mathrm{S}}=0 \\
& \mathrm{w} / 18 \ll \mathrm{W} / 18
\end{aligned}
$$

then equations 22 and 23 have the simultaneous solution:

$$
\begin{aligned}
& x_{a}=\left[\frac{Q_{a}+E x_{g}+I_{i n} x_{a_{o}}}{I_{i n}+E}\right] \rho_{a} \\
& x_{g}=\left[\frac{P_{a}+R_{i n} x_{g_{o}}}{R_{i n}+P+W / 18}\right]
\end{aligned}
$$

The solution of these equations for each latitude belt becomes quite complex, since, due to the evaporation and precipitation processes, an inflow of tritiated surface water into a latitude belt also represents a source of tritiated water vapor to the atmosphere. Thus the equations would have to be solved simultaneously for each latitude belt by establishing the values of $x_{0}$ and $x_{g_{0}}$ from adjacent latitude 
belts. As seen from Figure 4.5 obtained from values published in Sellers (1965), there is a mean northward transport of water vapor, and consequently (based on the above assumptions) a mean southward transport of surface water throughout the mid-latitudes of the northern hemisphere. The reverse is true of the tropical latitudes, and the subtropics represent a major source of water vapor and sink of surface water. To avoid the complexity of these solutions it is assumed for this analysis that

$$
\begin{aligned}
& \text { At latitude } 30^{\circ}-50^{\circ} \mathrm{N}: \quad \chi_{a_{0}}=0 \\
& x_{g_{0}}=0
\end{aligned}
$$

A11 other latitude belts: $Q_{a}=0$

This analysis assumes in addition that tritium concentrations are spread uniformly throughout the $30^{\circ}-50^{\circ}$ belt, the latitude belt in which all the sources occur, due to the north-south eddy meridional transport properties of the traveling cyclones, but that outside this belt the transport of tritiated water vapor and liquid water is performed entirely by the mean meridional transport of water vapor and liquid water. To avoid one additional computational difficulty, a southward eddy water vapor transport term across the $30^{\circ}$ meridian was lised to determine $x_{a_{0}}$ for the $20^{\circ}-30^{\circ}$ belt. Values of the parameters needed to solve equations (28) and (29) are shown in Table 4.2. Table 4.3 gives the results of the computation for two choices of $W: W=0.5 \mathrm{~m}$ (1and areas) and $W=75 \mathrm{~m}$ (oceans). 


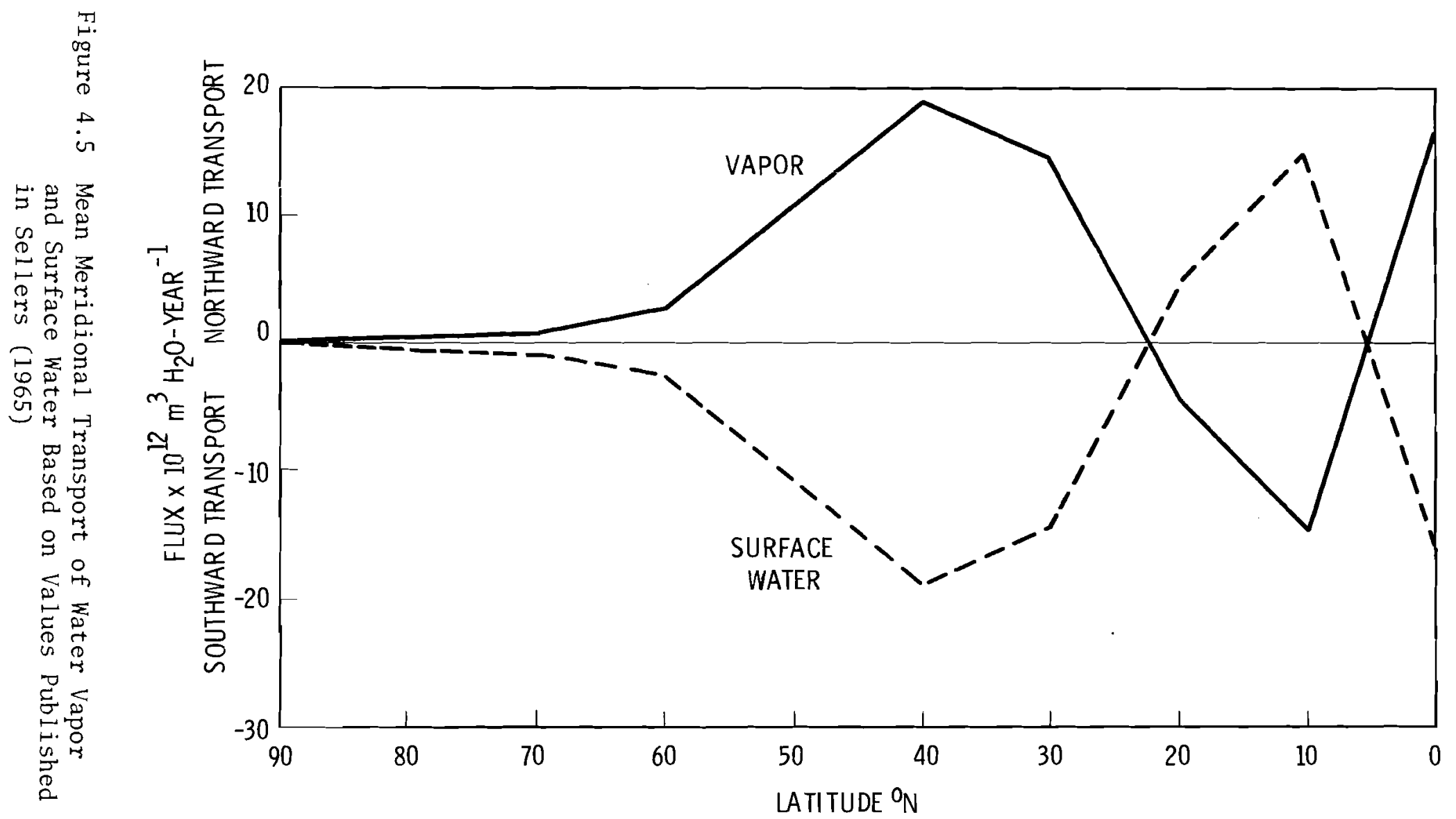




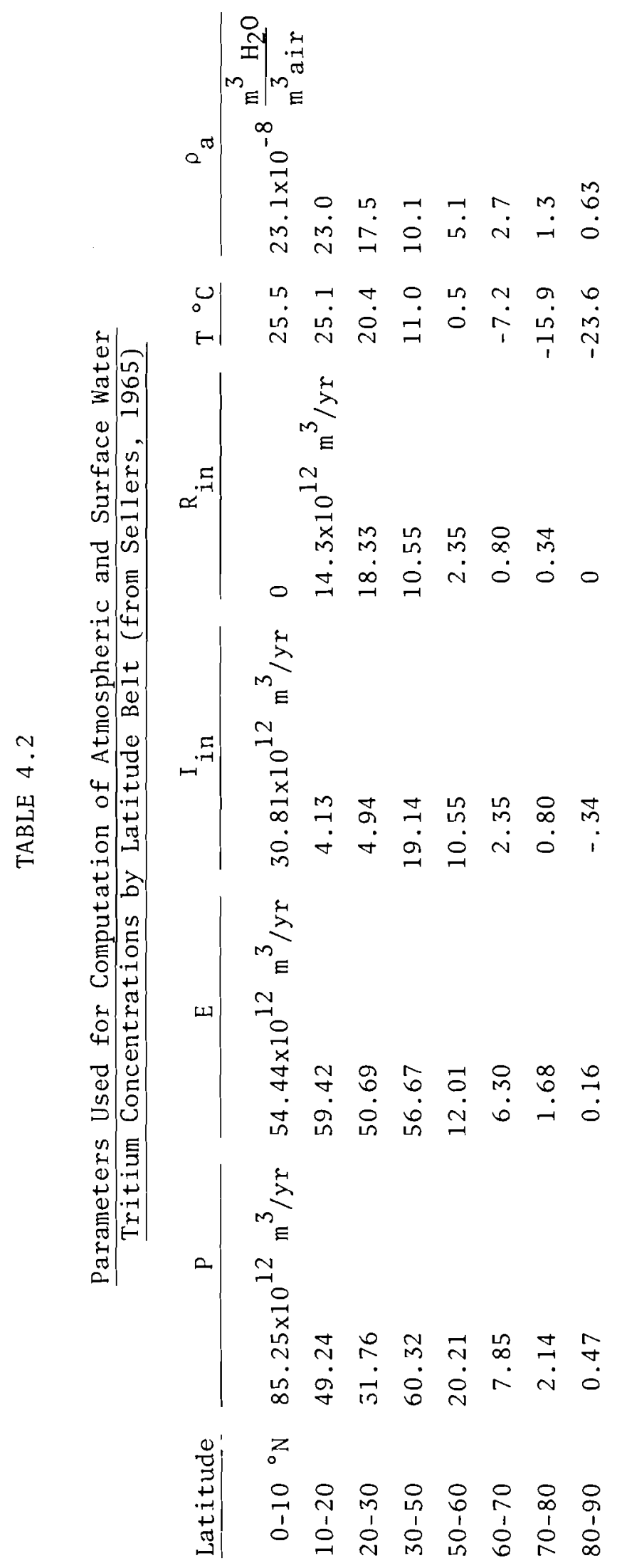




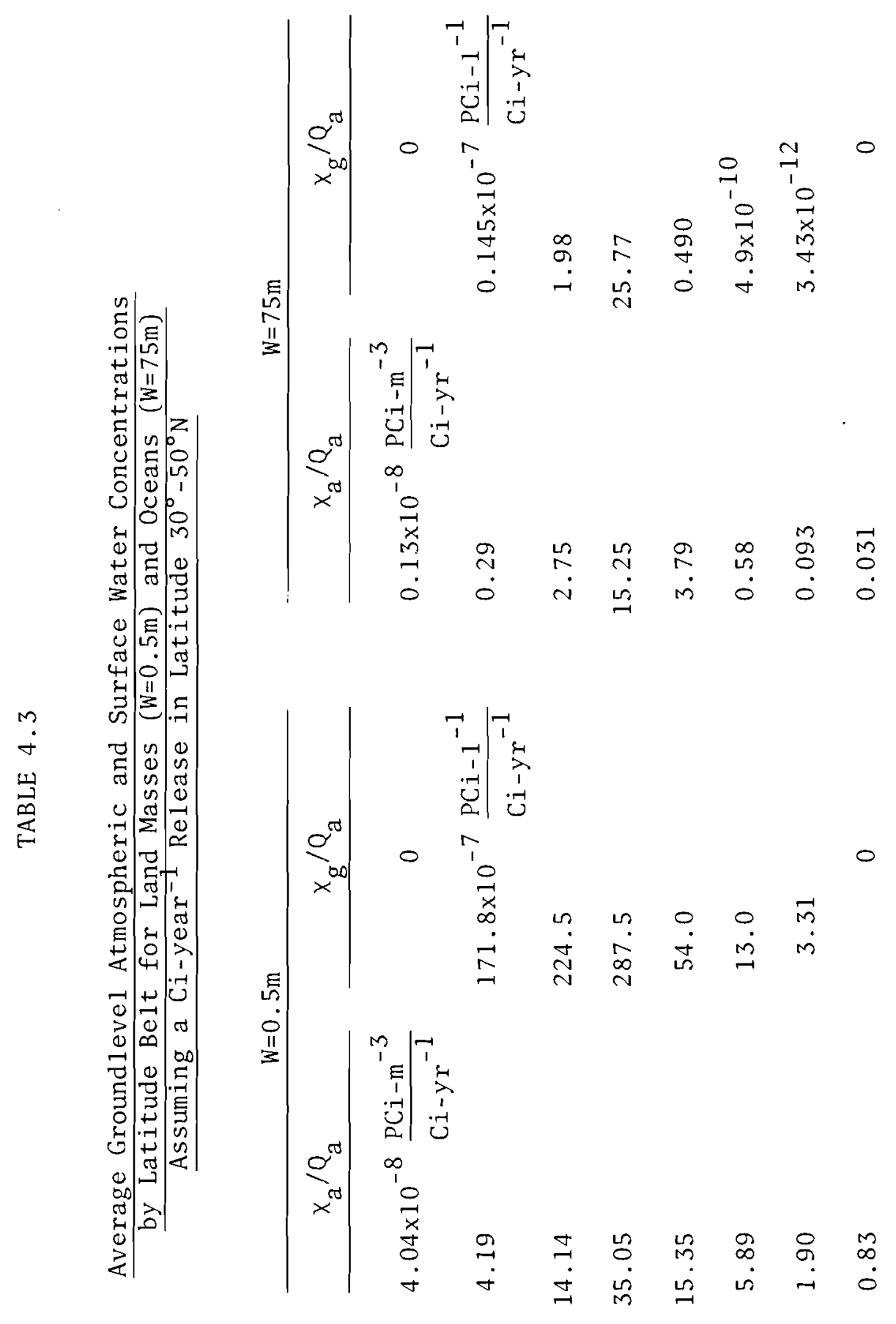

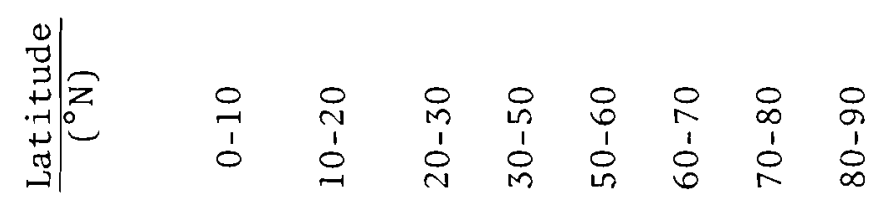


The assumptions noted above which are needed to simplify the complexity of the solution result in an underestimate of tritium concentrations. This is a result of a failure to reestablish new values of $x_{a_{0}}$ and $x_{g_{0}}$ as concentrations for each latitudinal belt are made. Thus a "background" estimate of tritium concentrations was established by solving equations (28) and (29) globally. Under this condition $I, x_{a_{0}}, x_{g_{0}}$, and $R$ must equal zero and $P=E$. Thus:

$$
\begin{aligned}
& \frac{X_{a}}{Q_{a}}=\left(\frac{18}{W A}+\frac{1}{E}\right) \rho_{a} \\
& \frac{X_{g}}{Q_{a}}=\frac{18}{W A}
\end{aligned}
$$

Globally, $E=1.47 \times 10^{14} \mathrm{~m}^{3}-y^{-1}$. Again, using the extreme values for $W$ of $0.5 \mathrm{~m}$ (1and) and $75 \mathrm{~m}$ (oceans) the global tritium concentrations can be summarized as follows:

$$
\begin{array}{rlr}
\frac{X_{a}}{Q_{a}} & =2.68 \times 10^{-6} & (W=0.5 \mathrm{~m}) \\
& =3.71 \times 10^{-8} & (W=75 \mathrm{~m}) \\
\frac{X_{g}}{Q_{a}} & =2.42 \times 10^{-4} & (W=0.5 \mathrm{~m}) \\
& =6.65 \times 10^{-7} & (W=75 \mathrm{~m})
\end{array}
$$

Since these background concentrations are much larger than the estimates shown for each latitude belt, it becomes evident that, based on this technique, the gradients of tritium concentrations across the 
latitude belts are quite small, despite the total source occurring in only one of the belts. Thus, Table 4.4 summarizes the estimated atmospheric and surface water concentrations incorporating this "background" value.

It can be seen from Table 4.3 and 4.4 that the selection of $W$, the readily mixed depth of groundwater, is quite critical to the computations in the range of 0.5 to 75 meters. This is particularly true of the surface water computations. Figure 4.6 shows a plot of the variation of normalized tritiated water concentration per unit area with $W$ for the values of $P, E, I$ and $R$ in the $30^{\circ}-50^{\circ}$ latitude belt. The variation occurs mostly in the $0.1 \mathrm{~m}$ to $100 \mathrm{~m}$ range. Libby (1963) used a value of $W=0.5 \mathrm{~m}$ for the North American land mass, but Begemann and Libby (1957) determined $W$ to be 8 meters for the Mississippi watershed. The value of 0.5 meters over land was selected for this phase of the study to obtain the most conservative estimates of surface water concentrations. Jacobs (1968) shows that the value of 75 meters for the oceans is acceptable.

A simple box model calculation over the $30^{\circ}-50^{\circ}$ latitude belt was made to provide a check on the values given in Table 4.3. By assuming mass inflow of clean air through the top half of a vertical column bounded by the $30^{\circ}$ latitude on one side and $50^{\circ}$ latitude on the other, and extending to the top of the atmosphere, and mass outflow of tritiated air from the bottom half of the column, atmospheric concentrations of tritium throughout the column can be determined from: 
TABLE 4.4

Average Ground-Level Atmospheric and Surface Water Concentrations by Latitude Belt for Land and Ocean Areas Incorporating the Global "Background"

\begin{tabular}{|c|c|c|c|c|c|c|}
\hline \multirow[b]{2}{*}{ Latitude $\left({ }^{\circ} \mathrm{N}\right)$} & \multicolumn{4}{|c|}{ LAND } & \multicolumn{2}{|c|}{ OCEANS } \\
\hline & $x_{a} / Q$ & $\frac{\mathrm{pCi}-\mathrm{m}^{-3}}{\mathrm{Ci-yr^{-1 }}}$ & $x_{g} / Q$ & $\frac{\mathrm{pCi-1}}{\mathrm{Ci-yr^{-1 }}}$ & $x_{a} / Q$ & $x_{g} / Q$ \\
\hline $0-10$ & 2.72 & $\times 10^{-6}$ & 2.42 & $\times 10^{-4}$ & $3.84 \times 10^{-8}$ & $6.65 \times 10^{-7}$ \\
\hline $10-20$ & 2.72 & & 2.59 & & 4.00 & 6.79 \\
\hline $20-30$ & 2.82 & & 2.64 & & 6.46 & 8.63 \\
\hline $30-50 *$ & 3.03 & & 2.69 & & 18.96 & 32.42 \\
\hline $50-60$ & 2.83 & & 2.47 & & 7.50 & 7.14 \\
\hline $60-70$ & 2.74 & & 2.43 & & 4.29 & 6.65 \\
\hline $70-80$ & 2.70 & & 2.42 & & 3.80 & 6.65 \\
\hline $80-90$ & 2.69 & & 2.42 & & 2.74 & 6.65 \\
\hline Global ** & 2.68 & & 2.42 & & 3.71 & 6.65 \\
\hline
\end{tabular}

* Source latitude belt

** "Background" 


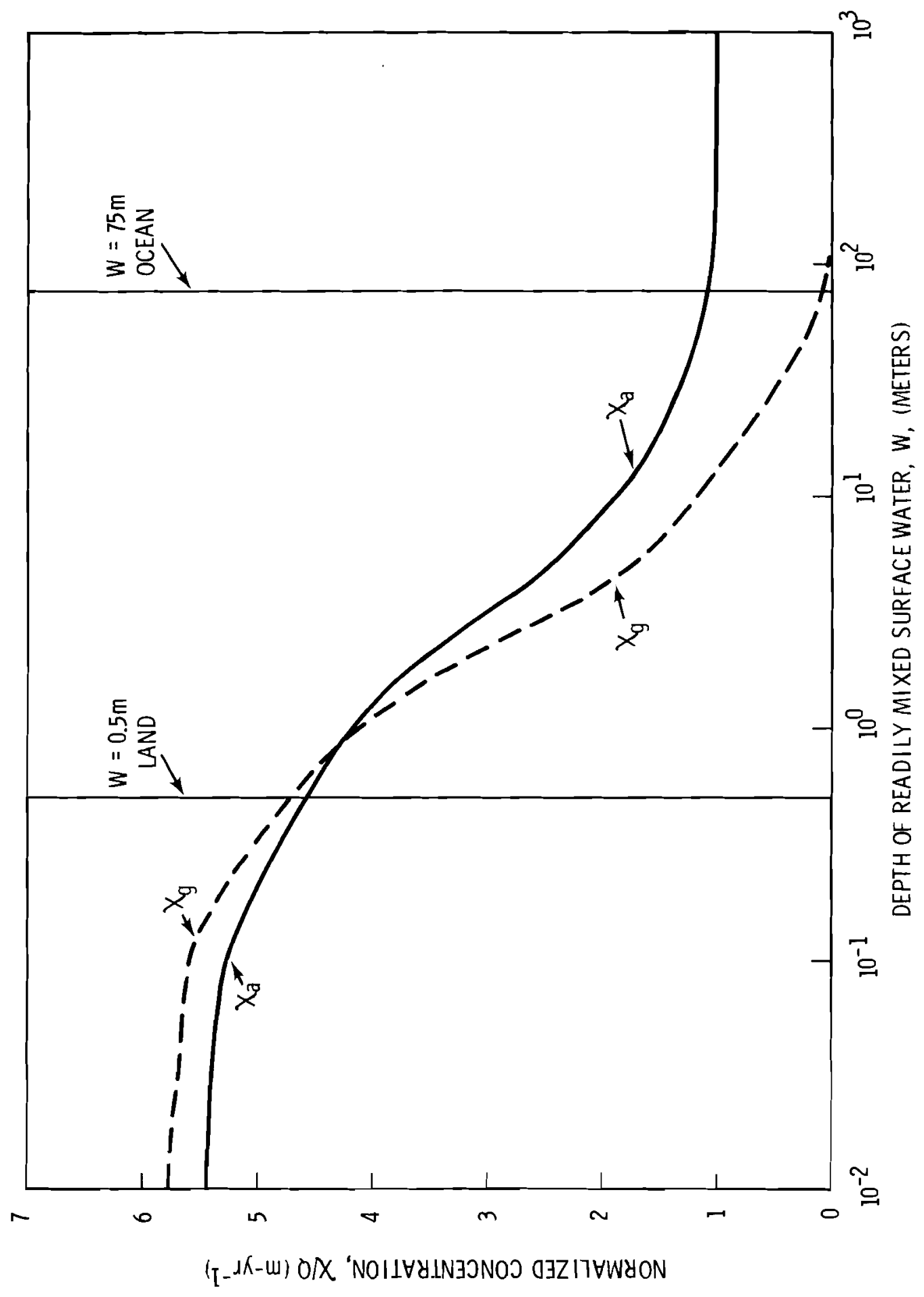

Figure 4.6 Variation of Normalized Tritiated Water Concentration Per Unit Area. 


$$
\frac{x_{a}}{Q_{a}}=\frac{2}{C_{n} L H}
$$

where:

$$
\begin{aligned}
\mathrm{C}_{\mathrm{n}}= & \text { average wind vector normal to the latitude belt } \\
& \text { for the outflow } \\
\mathrm{L}= & \text { length of the latitude boundary } \\
\mathrm{H}= & \text { height of column }
\end{aligned}
$$

The value of $C_{n}$ was determined from Palmén and Newton (1969) to be $0.5 \mathrm{~m}-\mathrm{sec}^{-1}$. Using $\mathrm{H}=10^{4} \mathrm{~m}$ and $\mathrm{L}=3.07 \times 10^{7} \mathrm{~m}\left(40^{\circ} \mathrm{N}\right)$ :

$$
\frac{X_{a}}{Q_{a}}=4.13 \times 10^{-7} \frac{\mathrm{pCi-m^{-3 }}}{\mathrm{Ci-yr^{-1 }}}
$$

which is in close agreement with the value shown for the $30^{\circ}-50^{\circ}$ belt in Table 4.3 (no "background"), particularly for $W=0.5 \mathrm{~m}$.

\subsection{Summary of Normal Operation Impacts}

The information in Figure 4.1 and 4.2 and in Tables 4.1 and 4.4 allow computations of the maximum allowable emissions (MAE) of a CTR based on the analysis procedure used here and the maximum permissible concentrations (MPC) that have been developed for HTO. For atmospheric tritium the MPC is $5 \times 10^{-6} \mathrm{Ci}_{-\mathrm{m}^{-3}}$, and for tritium in the drinking water supply the MPC is $1 \times 10^{-4} \mathrm{Ci}-1$ iter. Thus a value for the maximum allowable emission for a CTR is the ratio of the MPC to the normalized atmospheric or surface water concentration estimate: 


$$
\text { MAE }=\frac{\text { MPC }}{x_{a} / Q \text { or } x_{g} / Q}
$$

A summary of maximum allowable emissions based on atmospheric and surface water estimates is given in Table 4.5. It is evident from this table that atmospheric concentrations represent the limiting factors for a CTR operation near the plant, while surface water concentrations represent the limiting factors at great distances from the plant. However, it is also evident that large quantities of tritium releases could be tolerated according to this analysis - quantities that far exceed the emission currently expected by a CTR technology.

\section{TABLE 4.5}

Summary of Maximum Allowable Emissions (MAE) of Tritium to the Atmosphere by a Normal CTR Operation Based on Atmospheric $\left(x_{a}\right)$ and Surface Water $\left(x_{g}\right)$ Concentrations

\begin{tabular}{ccc} 
& $x_{\mathrm{a}}$ & $x_{\mathrm{g}}$ \\
\hline Phase & $\frac{\left(\mathrm{Ci}-\mathrm{yr}^{-1}\right)}{\left(\mathrm{Ci}-\mathrm{yr}^{-1}\right)}$ \\
1 & $6.2 \times 10^{9}$ & $9.2 \times 10^{9}$ \\
2 & $5.0 \times 10^{10}$ & $2.8 \times 10^{10}$ \\
3 & $1.6 \times 10^{12}$ & $3.7 \times 10^{11}$
\end{tabular}




\subsection{Accidental Releases of Tritium}

One of the major concerns in a CTR accident situation is that large quantities of tritium will be released into the environment due to a liquid metal fire burning through the containment vessel. The impact of such an accident on the atmosphere and surface water environment can be analyzed in two ways -- by describing the worse (i.e., most stable) meteorological conditions and thereby maximizing the groundlevel atmospheric tritium concentration calculations, or by describing a situation where a large portion of the accidental release will be scavenged by a precipitation system and mixed in with the surface water supply almost immediately. Since surface water concentrations could ultimately affect a large part of the general population, this aspect of an accidental release will be analyzed here.

The analysis procedure involves the same basic approach that was used to estimate surface water concentrations during routine operations. This approach, assuming equilibrium conditions, will produce conservative results for distances near the emission source (See Figure 3.1). The relation for determining surface water tritium concentrations, $x_{g}$, is given by

$$
\frac{x_{g}}{Q_{t}}=\left\{\frac{1-\exp \left[-k_{e q}\left(\frac{x}{\bar{u}}\right)\right]}{A W}\right\}
$$


where:

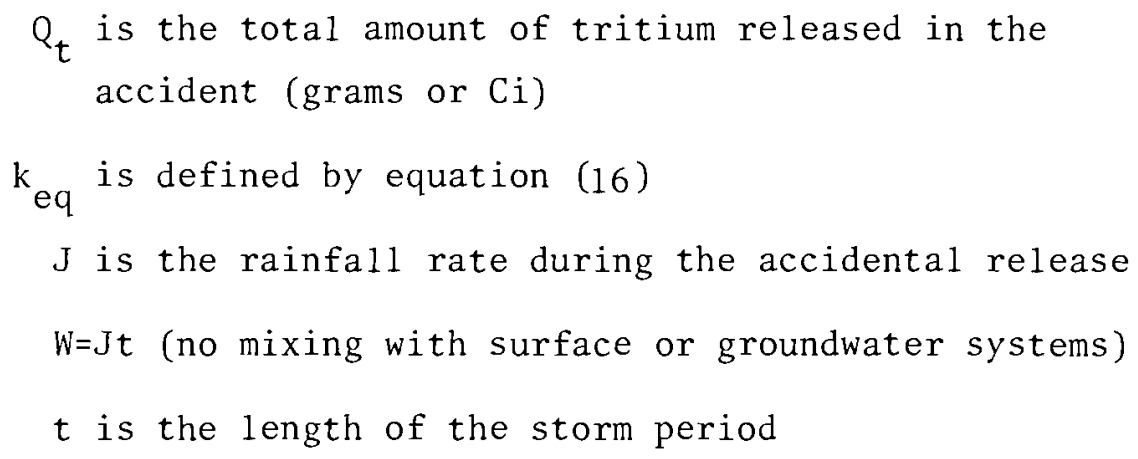

The value of $J$ was determined from rainfall frequency curves published in Linsley, et a1., (1958). For Phase 1 the maximum expected rainfall rate within a 100 -year period in the vicinity of Morris, Illinois is $75 \mathrm{~mm}_{\text {-hour }}^{-1}$. For Phase 2 the maximum daily rainfall expected within a 50-year period near Morris, Illinois is $125 \mathrm{~mm}^{-\mathrm{day}^{-1}}{ }^{-1}$ For this analysis, $\mathrm{H}^{*}=1.05 \times 10^{-5}\left(\mathrm{~T}=286.7^{\circ} \mathrm{K}\right)$, $\sigma_{z}^{\prime}=859$ meters, $\bar{u}=4.05 \mathrm{~m}-\mathrm{sec}^{-1}$, and $t=3600 \mathrm{sec}$ for Phase 1 and $8.64 \times 10^{5} \mathrm{sec}$ for Phase 2 .

Results of the Phase 1 and 2 accident analyses are given in Table 4.6. Based on these rainfall rates any accidental release of tritium would be scavenged almost immediately within a distance of 10 kilometers for Phase 1, and within a distance of 150 kilometers for Phase 2. Assuming the values of $x_{g} / Q_{a}$ in Table 4.4 are representative of normalized concentrations that would be found in the drinking water in the plant vicinity after an accident, the maximum permissible concentrations would be exceeded if an accidental release of greater than 68 grams under Phase 1 conditions, and 128 kilograms under Phase 2 
conditions. Thus a postulated $10 \mathrm{kgm}$ accidental release of tritium could result in severe environmental impacts, particularly in the immediate vicinity of the plant, under these meteorologic conditions.

The effect of rainfall rate on surface water concentrations at various distances from the site is shown in Figure 4.7. Since no groundwater mixing is assumed a large rainfall rate actually represents greater dilution, with highest concentrations occurring for light rainfal1s. However many other factors enter into these computations including the manner in which the scavenging coefficient is computed (See Section 3), and the depth of surface water available for mixing with rainwater. The figure also shows the concentration estimated for a postulated $10 \mathrm{kgm}$ release of tritium.

Although the results of an analysis such as this emphasize the need to develop every possible safeguard against a CTR accident, there is also a need to develop estimates on the probability of such accidents occurring under the conditions described above. In addition there is a need to investigate further environmental conditions that might exist which could result in even greater impacts from a CTR accident. These investigations require a detailed statistical evaluation of climatological data, as well as a complete analysis of potential CTR accident situations. 
TABLE 4.6

Surface Water Concentrations of Tritium During Occurrence of Maximum Rainfall Rates Following a CTR Accident

\begin{tabular}{|c|c|c|c|c|c|}
\hline \multicolumn{3}{|c|}{ Phase $1 \quad\left(J=75 \mathrm{~mm}-\mathrm{hr}^{-1}\right)$} & \multicolumn{3}{|c|}{ Phase $2\left(\mathrm{~J}=125 \mathrm{~mm}-\mathrm{day}^{-1}\right)$} \\
\hline $\mathrm{x}(\mathrm{km})$ & $\Delta \mathrm{f}^{*}$ & $x_{g} / Q_{t}\left(1^{-1}\right)$ & $x(\mathrm{~km})$ & $\Delta f$ & $x_{g} / Q_{t}\left(1^{-1}\right)$ \\
\hline 5 & .1035 & $1.6 \times 10^{-10}$ & 50 & .7939 & $8.1 \times 10^{-14}$ \\
\hline 10 & .0911 & $5.3 \times 10^{-12}$ & 100 & .1637 & $5.5 \times 10^{-15}$ \\
\hline 15 & .0110 & $3.9 \times 10^{-13}$ & 150 & .0337 & $6.8 \times 10^{-16}$ \\
\hline & & & 200 & .0069 & $1.0 \times 10^{-16}$ \\
\hline
\end{tabular}

* See Table 4.1 for explanation 


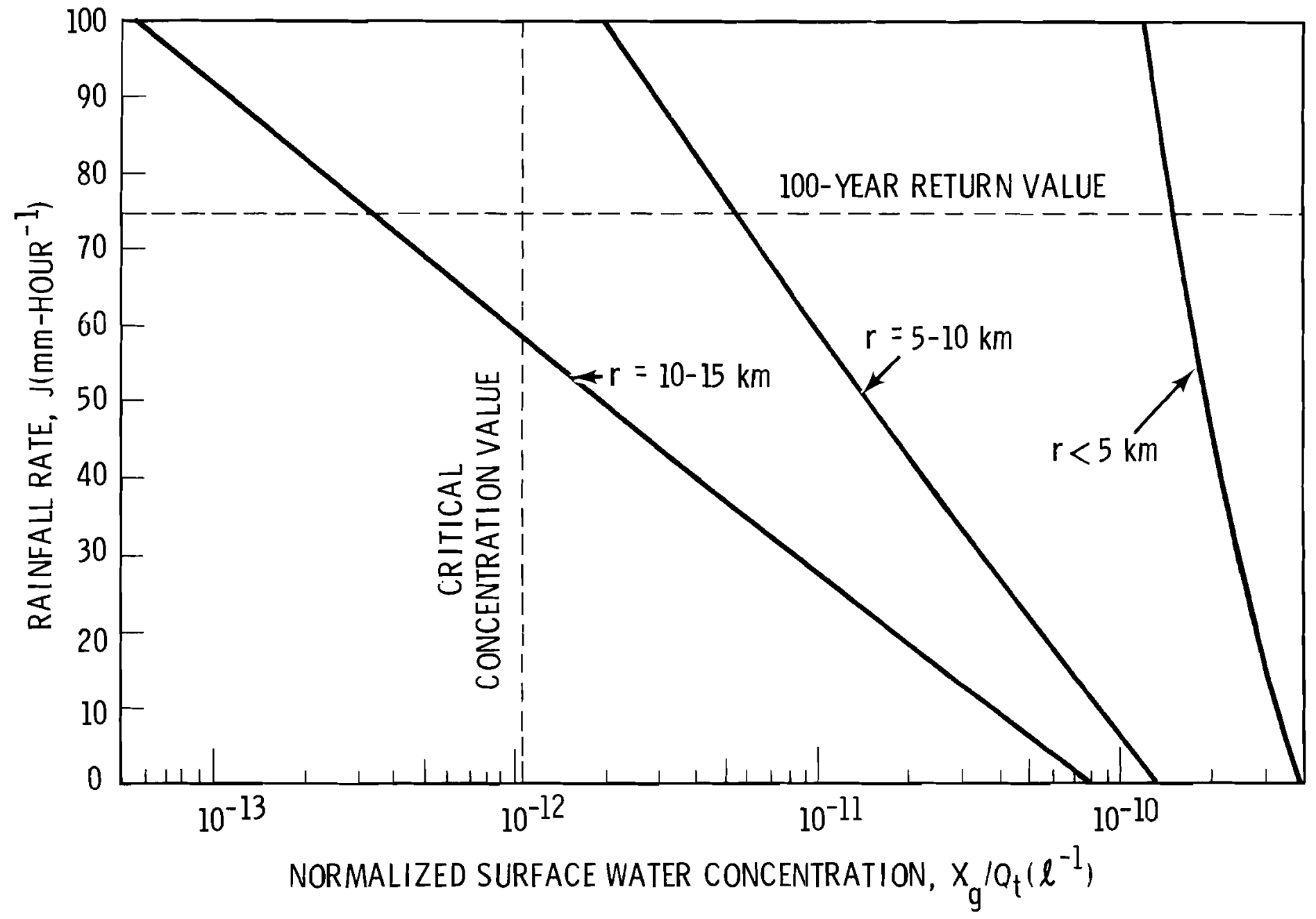

Figure 4.7 The Effect of Rainfall Rate on Normalized Surface Water Concentration. 


\section{CONCLUSIONS AND FUTURE RESEARCH NEEDS}

This analysis has shown that the normal operation of a commercial CTR in the vicinity of Morris, Illinois should have a small impact on the environment in terms of increased tritium concentrations in the air and surface water. This, of course, assumes that CTR operations do not emit

quantities of tritium exceeding $10^{3} \mathrm{kgm}$ per year. In addition, the limits to these normal tritium releases to the atmosphere appear to be controlled by atmospheric concentrations in the vicinity of the plant (Phases 1 and 2). However, as tritium becomes an integral part of the hydrologic cycle (Phase 3) surface water concentrations become the limiting factor. Although the total body dose is determined both from atmospheric exposure and ingestion, the maximum permissible concentrations in drinking water are much more stringent than in the atmosphere. Furthermore, the assumption that all tritium releases will be in the form of tritiated water vapor places a higher constraint on the allowable emissions, since the ICRP-recommended occupational maximum permissible concentration for elemental tritium in air is 400 times higher than for tritium oxide in air (Young, et al., 1975).

The analysis also considered accidental releases of tritiated water vapor into the atmosphere coinciding with an unusually severe precipitation event. Assuming no mixing with groundwater, this analysis showed that maximum a1lowable concentration standards of tritium in the surface water (and thus drinking water) supplies would be exceeded by 1 to 2 orders of magnitude if the estimated accidental release of $10 \mathrm{kgm}$ of tritium is postulated. 
Several topics requiring additional research have been identified during the completion of this analysis. More sophisticated modeling techniques for transport over several hundreds of kilometers are required, particularly if complex terrain and land-sea contrasts are to be included. For example, some success has been obtained using numerical boundary layer models to estimate tritium concentrations in the vicinity of the Savannah River Laboratory (Kern, 1974). The manner in which HTO enters into the hydrologic cycle, and the similarities between $\mathrm{HTO}$ and $\mathrm{H}_{2} \mathrm{O}$ need further quantification. This becomes particularly important when examining the scavenging process of HTO by precipitation, and the subsequent return to the atmosphere via the evapotranspiration process. Research into the probabilities of large accidental releases during unfavorable meteorological episodes needs to be undertaken.

Despite the fact that this initial analysis showed normal releases of tritium due to a commercial CTR technology to have a relatively small impact on the environment, the need for stringent control of CTR tritium releases must be emphasized. In addition, developing a CTR technology could produce large and perhaps serious secondary impacts on the atmosphere due to massive construction programs, industrial development, and large influxes of population into unpopulated regions. In addition, considerations must be made to avoid serious emissions of tritium when a commercial CTR facility is finally decommissioned. Above all, stringent controls must be pursued to avoid large releases of tritium during an accident situation. 


\section{REFERENCES}

Begemann, F. and W. F. Libby, 1957: Continental Water Balance, Ground Water Inventory and Storage Times, Surface Ocean Mixing Rates and Wor 1dWide Water Circulation Patterns from Cosmic Ray and Bomb Tritium. Ceochim. Cosmochim. Acta 12(4): 277-296.

Booker, D. V., 1965: Exchange Between Water Droplets and Tritiated Water Vapor. Quart. J. Roy. Met. Soc. 91: 73-79.

Dana, M. Terry, J. M. Hales and M. A. Wolf, 1972: Natural Precipitation Washout by Sulfur Dioxide. BNWL-389, Battelle, Pacific Northwest Laboratories, Richland, Washington.

Dana, M. Terry, J. M. Hales, W.G.N. Slinn, and M. A. Wolf, 1973: Natural Precipitation Washout of Sulfur Compounds from Plumes. EPA-R3-73-047, Battelle, Pacific Northwest Laboratories, Richland, Washington.

Dickerson, M. H. and T. V. Crawford, 1972: In-cloud Precipitation Scavenging of Tritiated Water Vapor. UCRL-51283, Lawrence Livermore Laboratory, Livermore, California.

Engelmann, R. S., 1965: The Calculation of Precipitation Scavenging. BNWL-77, Batte1le, Pacific Northwest Laboratories, Richland, Washington.

Friedman, Irving, Lester Machta and Ralph Soller, 1962: Water-vapor Exchange Between a Water Droplet and Its Environment. J. Geophys. Res. $67(7): 2761-2766$.

Hales, J. M., 1972a: Fundamentals of the Theory of Gas Scavenging by Rain. Atmospheric Environment 6: 635-659.

Hales, J. M., 1972b: Scavenging of Gaseous Tritium Compounds by Rain. BNWL-1659, Battel1e, Pacific Northwest Laboratories, Richland, Washington.

Heffter, Jerome L., Albion D. Taylor and Gilbert J. Ferber, 1975: A Regional-continental Scale Transport, Diffusion, and Deposition Mode1. NOAA Technical Memorandum ERL ARL-50, Air Resources Laboratory, Silver Spring, Maryland.

Jacobs, D. G., 1968: Sources of Tritium and Its Behavior Upon Release to the Environment. U.S. Atomic Energy Commission, Division of Technical Information, $90 \mathrm{pp}$.

Kern, C. D., 1974: A Simple Model to Determine Mesoscale Transport of Airborne Pollutants. Proceedings of the Symposium on Atmospheric Diffusion and Air Pollution, Santa Barbara, California, September 9-13, 1974 . 
Libby, W. F., 1963: Moratorium Tritium Geophysics. J. Geophys. Res. $68(15)$ : 4485-4494.

Linsley, Ray K., Max A. Kohler and Joseph L.H. Paulhus, 1958: Hydrology for Engineers. McGraw-Hil1 Book Company, Inc., New York. 340 pp.

Machta, Lester, Gilbert J. Ferber and Jerome L. Heffter, 1973: Local and World-wide Pollutant Concentrations and Population Exposures from a Continuous Point Source. Air Resources Laboratories, National Oceanic and Atmospheric Administration, Silver Spring, Maryland, 20910.

Palmen, E. and C. W. Newton, 1969: Atmospheric Circulation Systems. Academic Press, New York. 603 pp.

Sellers, William D., 1965: Physical Climatology. The University of Chicago Press, Chicago. $272 \mathrm{pp}$.

Smith, M. E. and I. A. Singer, 1966: An Improved Method of Estimating Concentrations and Related Phenomena from a Point Source Emission. J. Appl. Meteor 1. 5: 631-639.

Young, J. R., et al., 1975: Information Requirements for Controlled Thermonuclear Reactor Environmental Impact Statements. BNWL-1883, Battelle, Pacific Northwest Laboratories, Richland, Washington. 


\section{DISTRIBUTION}

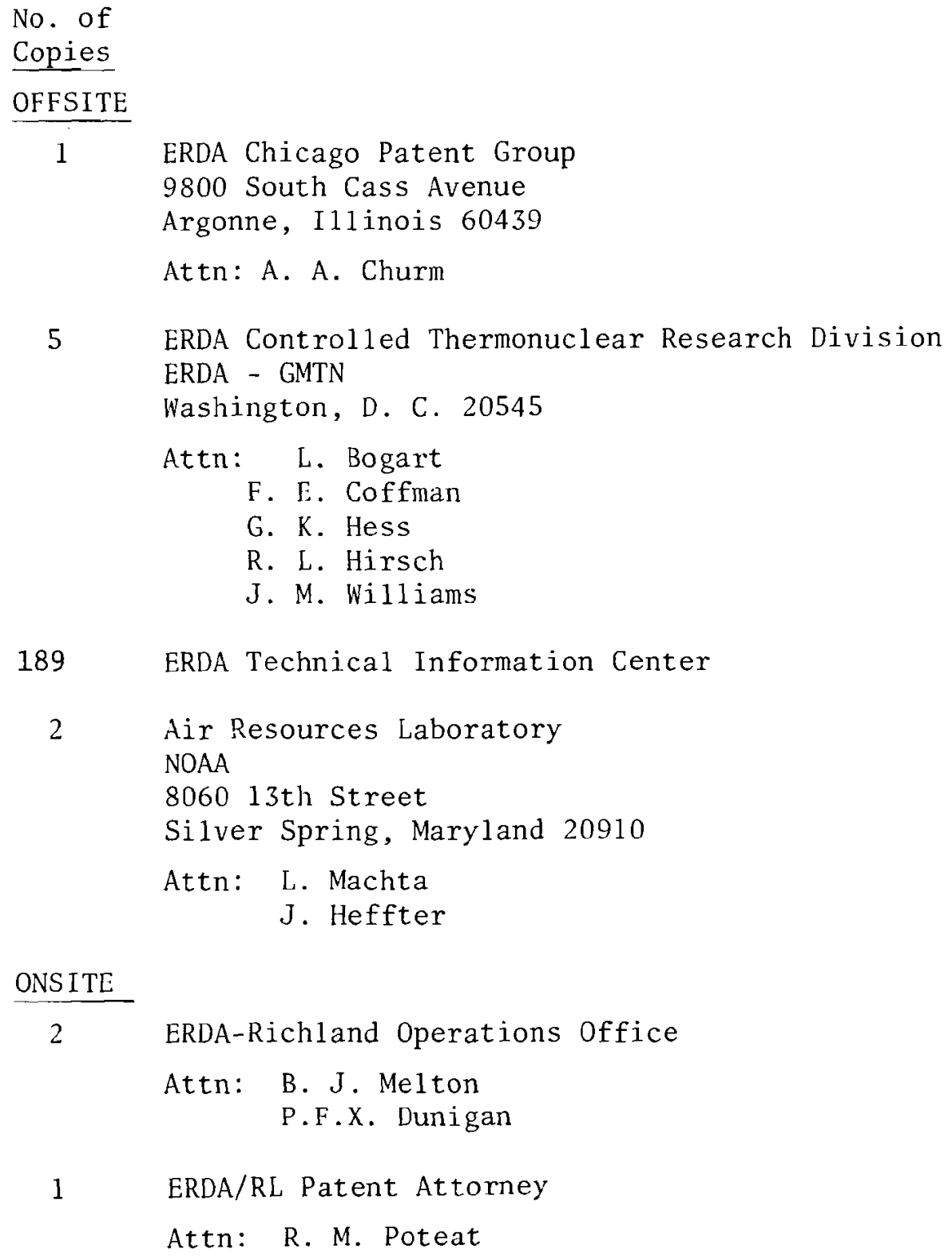


No. of

Copies

ONSITE

48 Battelle-Northwest

Attn: W. J, Bair

D. A. Baker

R. G. Clark

M. T. Dana (2)

D. L. Elliott

J. M. Hales

A. B. Johnson

D. S. Renné (25)

W. F. Sandusky (5)

L. C. Schmid

C. L. Simpson

E. C. Watson

L. L. Wende 11

R. K. Woodruff

J. R. Young

Technical Information (3)

Technical Publications 